\title{
Porous APS YSZ TBC Manufactured at High Powder Feed Rate (100 g/min) and Deposition Efficiency (70\%): Microstructure, Bond Strength and Thermal Gradients
}

\author{
Rogerio S. Lima ${ }^{1}$
}

Submitted: 6 September 2021 / in revised form: 26 October 2021/Accepted: 26 November 2021/Published online: 4 January 2022 (C) Crown 2022

\begin{abstract}
There is a strong driving force to improve the production efficiency of thermal barrier coatings (TBCs) manufactured via air plasma spray (APS). To address this need, the high-enthalpy APS torch Axial III Plus was employed to successfully manufacture TBCs by spraying a commercial YSZ feedstock at powder feed rate of $100 \mathrm{~g} /$ min using an optimized set of $\mathrm{N}_{2} / \mathrm{H}_{2}$ spray parameters; which yielded an impressive YSZ deposition efficiency (DE) value of $70 \%$. This exact same set of optimized spray parameters was used to manufacture the same identical YSZ TBC (over $\sim 160 \mu \mathrm{m}$-thick bond-coated substrates) but at two distinct YSZ thickness levels: (i) $\sim 420 \mu \mathrm{m}$ thick and (ii) $\sim 930 \mu \mathrm{m}$-thick. In spite of the high YSZ feed rate and DE levels, the YSZ TBC revealed a $\sim 14 \%$ porous (conventional looking) microstructure, without segmented cracking or horizontal delamination at both thickness levels. The bond strength values measured via the ASTM C633 standard for the $\sim 420 \mu \mathrm{m}$-thick and $\sim 930 \mu \mathrm{m}$-thick YSZ TBCs were $\sim 13.0$ and $\sim 11.6 \mathrm{MPa}$ (respectively); which are among at the upper end values reported in the literature. After the first objective was attained, the second key objective of this work was to evaluate the thermal insulating effectiveness of these two as-sprayed YSZ TBCs. To achieve this objective, a thermal gradient laser-rig was employed to generate a temperature reduction $(\Delta \mathrm{T})$ along the TBC-coated coupons under different laser power levels. These distinct laser power levels generated YSZ TBC surface temperatures varying for 1100 to $1500{ }^{\circ} \mathrm{C}$, for the $\sim 420 \mu \mathrm{m}$-thick YSZ TBC, and from
\end{abstract}

Rogerio S. Lima

rogerio.lima@cnrc-nrc.gc.ca

1 National Research Council of Canada, 75 de Mortagne Blvd, Boucherville, QC J4B 6Y4, Canada
1100 to $1680{ }^{\circ} \mathrm{C}$ YSZ TBC $\sim 930 \mu$ m-thick YSZ TBC. The respective $\Delta \mathrm{T}$ values for both TBCs are reported. The results of this engineering paper are promising regarding the possibility of improving considerably the manufacturing efficiency of industrial quality conventional-looking porous YSZ TBCs, by using a high-enthalpy $\mathrm{N}_{2}$-based APS torch. This is the first paper published in the open literature showing R\&D results of coatings manufactured via the Axial III Plus APS torch.

Keywords APS · bond strength · deposition efficiency (DE) - high-enthalpy torch $\cdot \mathrm{N}_{2}$-based plasma $\cdot$ TBC . thermal gradient . YSZ

\section{Introduction}

\section{Thermal Barrier Coatings (TBCs) Manufactured Via Air Plasma Spray (APS)}

TBCs manufactured via APS provide thermal insulation from the hot combustion gas stream to the static metallic parts located in the hot sections of gas turbine engines (e.g., combustion chambers, nozzles and afterburners). A thermally sprayed TBC system typically exhibits a bi-layered structure, which includes a ceramic top coat and a metallic $\operatorname{MCrAlY}(\mathrm{M}=\mathrm{Ni}, \mathrm{Co}, \mathrm{NiCo}$ or $\mathrm{CoNi}$ ) bond coat (BC). The ceramic top coat (e.g., $\mathrm{ZrO}_{2}-7-8 \mathrm{wt} . \% \mathrm{Y}_{2} \mathrm{O}_{3}$, a.k.a., YSZ) provides thermal insulation and reduces the heat flow to the turbine metallic part; which is made of a Ni-based high temperature superalloy (e.g., Hastelloy X). The metallic MCrAlY BC is an oxidation/corrosion-resistant metallic layer. It protects the underlying component and improves the adhesion of the ceramic top coat on the part. More detailed information about TBC manufacturing, properties 
and characteristics can be found in the work of Feuerstein et al. (Ref 1).

\section{TBC Manufacturing Efficiency}

Two critical aspects to be faced by the industry in the twenty-first century are the environment and sustainability. There is a huge driving force to avoid the depletion of natural resources in order to maintain an ecological balance. Reducing environmental footprint means reducing at the same time the amount of natural resources and energy used to produce a product. This need is now demanded in all sectors of the society, which includes the TBC market; more specifically the TBC manufacturing via thermal spray. According to Sampath et al. (Ref 2), in 2011 approximately 1-1.5 million $\mathrm{kg}$ of YSZ powders were sprayed onto turbine engine components via APS. It is important to point out that the huge majority of APS torches being employed in the world today are the so-called "legacy" types (e.g., 3MB, 9MB, F4 and variations of these); which use (i) $\mathrm{Ar} / \mathrm{H}_{2}$ as standard plasma gases, (ii) exhibit maximum power levels in the range of $40-80 \mathrm{~kW}$ and (iii) are usually limited to spray YSZ at maximum powder feed rates of $60 \mathrm{~g} / \mathrm{min}$. By understanding the key characteristics of these torches, one can foresee that the loss of the YSZ material is immense. One of the fundamental reasons is the low deposition efficiency (DE) values for YSZ when sprayed via these types of "legacy" equipment and using an $\mathrm{Ar} / \mathrm{H}_{2}$ plasma.

Marple et al. (Ref 3) compared the DE values of a YSZ powder when sprayed via a legacy $9 \mathrm{MB}$ torch using the standard $\mathrm{Ar} / \mathrm{H}_{2}$ versus the alternative $\mathrm{N}_{2} / \mathrm{H} 2$ plasma. Briefly, the YSZ DE values for the Ar/ $\mathrm{H}_{2}$ and $\mathrm{N}_{2} / \mathrm{H}_{2}$ plasmas were found to be in the range of $10-38 \%$ and 5-70\%; respectively. Other studies showed the same trend when legacy APS torches like the 3MB (Ref 4) and 9MB (Ref 5) were employed to spray YSZ. The YSZ DE values for $\mathrm{Ar} / \mathrm{H}_{2}$ plasmas were in the range of $30-43 \%$; whereas, those for $\mathrm{N}_{2} / \mathrm{H}_{2}$ plasmas were improved and reached $53-62 \%$ (without causing a drop in TBC performance with respect to thermal conductivity or thermal cycling).

Therefore, as the majority of the legacy APS torches operating today are using $\mathrm{Ar} / \mathrm{H}_{2}$ plasmas to spray $\mathrm{YSZ}$, it can be speculated that of the 1-1.5 million $\mathrm{kg}$ of YSZ powder material sprayed per year (Sampath et al. (Ref 2)), only about $40 \%$ will in fact become deposited on the turbine components. Consequently, over $50 \%$ of the YSZ powder material sprayed will be wasted in dust collectors. This is a serious issue.

The key reasons why $\mathrm{Ar} / \mathrm{H}_{2}$ plasmas yield lower DE values than those of $\mathrm{N}_{2} / \mathrm{H}_{2}$ ones can be understood by reading the work of Belashchenko and Zagorski (Ref 6). Chiefly, at the same range of plasma temperature conditions (e.g., from 10,000 to $12,000{ }^{\circ} \mathrm{C}$ ), $\mathrm{N}_{2}$-based plasmas exhibit higher enthalpy (i.e., heat content) levels than those of Ar-based ones. By giving one specific example, at $12,000{ }^{\circ} \mathrm{C}$, the enthalpy (kJ/liter) of the $\mathrm{N}_{2}$ plasma is $\sim 4 \mathrm{X}$ higher that of the Ar plasma. In addition, Murphy and Arundell (Ref 7) showed that for this same temperature plasma temperature range (i.e., 10,000$12,000{ }^{\circ} \mathrm{C}$ ), the thermal conductivity of $\mathrm{N}_{2}$ plasma varies from $\sim 1.5$ to $2.0 \mathrm{~W} / \mathrm{mK}$, whereas that of the Ar plasma ranges from $\sim 0.5$ to $1.5 \mathrm{~W} / \mathrm{mK}$. More specifically, at $12,000{ }^{\circ} \mathrm{C}$, the thermal conductivity of the $\mathrm{N}_{2}$ plasma is $\sim 30 \%$ higher than that of the Ar plasma. Consequently, the higher heat content and thermal conductivity values of $\mathrm{N}_{2}$-based plasmas (when compared to those of Ar-based) yield these known higher DE values during YSZ TBC manufacturing. As a side note, it needs to be mentioned that $\mathrm{H}_{2}$ is typically employed as a secondary gas for either Ar or $\mathrm{N}_{2}$ primary gas plasmas. The $\mathrm{H}_{2}$ gas increases even further the thermal conductivity (i.e., thermal efficiency) of the $\mathrm{Ar}$ and $\mathrm{N}_{2}$ primary plasmas. However, it does not significantly affect the fundamental heat content of the gas mixture $\left(\mathrm{Ar} / \mathrm{H}_{2}\right.$ or $\left.\mathrm{N}_{2} / \mathrm{H}_{2}\right)$, as described by Belashchenko and Zagorski (Ref 6).

In spite of the obvious advantages, $\mathrm{N}_{2}$-based plasmas typically have a "bad reputation" in the thermal spray community. The main reason is based on the fact that for these legacy torches, it tends to wear the torch copper $(\mathrm{Cu})$ nozzle (anode) at rates quicker than that of the Ar plasma. This accelerated erosion will lead to an earlier variation and destabilization of the plasma plume conditions, thereby leading to TBC manufacturing reliability problems. ElZein et al. (Ref 8) have shown that under similar gas flow levels, the current density $\left(\mathrm{A} / \mathrm{cm}^{2}\right)$ of a $\mathrm{N}_{2}$ plasma is $\sim 25 \%$ more intense than that of an $\mathrm{Ar}$ one. This superior current density is linked to an enhanced heat load of the nozzle wall and thus its accelerated erosion. Consequently, Ar is generally chosen as the standard primary plasma gas (mainly for the legacy APS torches), in spite of (i) the typically low YSZ DE values $(<50 \%)$ yielded by this gas and (ii) the usual maximum limitation of YSZ powder feed rate of $60 \mathrm{~g} / \mathrm{min}$ for $\mathrm{Ar} / \mathrm{H}_{2}$ legacy APS torches. However, this tendency for accelerated $\mathrm{Cu}$ nozzle erosion for $\mathrm{N}_{2}$ based plasmas can be counter-acted by employing tungsten-lined nozzles. On the other hand, even by using a $\mathrm{N}_{2}$ based plasma, these legacy torches are still limited to work at maximum power levels in the order to $40-80 \mathrm{~kW}$.

As another alternative that can be explored are more modern high-enthalpy APS torches. These torches are able to handle well power levels of approximately $100 \mathrm{~kW}$ (or even superior values) and are typically designed from the get-go to operate with $\mathrm{N}_{2}$-based plasmas. The combination of elevated plasma power levels $(\sim 100 \mathrm{~kW})$ with the $\mathrm{N}_{2}$ high enthalpy plasma gas has the potential improve 
significantly the manufacturing of YSZ TBCs, by concomitantly (i) enhancing YSZ DE levels to $>50 \%$ (i.e., reducing waste), (ii) allowing YSZ powder feed rates of $100 \mathrm{~g} / \mathrm{min}$ (or higher), thereby (iii) reducing the time needed to have a component coated. In addition to providing improved DEs, the cost per $\mathrm{m}^{3}$ of the $\mathrm{N}_{2}$ gas is $\sim 25 \%$ lower than that of the Ar (at same purity levels); which improves even further the manufacturing efficiency. Finally, concerns about the use of a $\mathrm{N}_{2}$-based plasmas can also be addressed by the use of computer-controlled consoles, mass-flow controllers, sensors, digital twin, big data and artificial intelligence (i.e., Industry 4.0 concepts). In this way, underdeveloped manufacturing issues can be detected and corrected before they become significant. There is an important future and a bright road of $\mathrm{R}$ and $\mathrm{D}$ activities in this area.

\section{Understanding Thermal Gradients within TBCs and Metallic Components}

TBCs reduce the temperature of the metallic components located in the hot section of gas turbine engines. These components, made from Ni-based superalloys (melting point $\sim 1300-1400{ }^{\circ} \mathrm{C}$ ), typically exhibit a wall thicknesses in the range of only $\sim 1-2 \mathrm{~mm}$. Moreover, they are subjected to elevated temperatures resulting from the hot stream of the combustion gases, which can reach a maximum peak of $2000{ }^{\circ} \mathrm{C}$ inside the combustion chamber. For this reason, the thermal insulation of the metallic turbine component is the "raison d'etre" of the TBC.

In spite of this fundamental importance, little information is available on the real thermal gradients generated across the overall thickness of $\mathrm{TBC} /$ metallic-component architectures (at least in the open literature). This type of information is paramount for engineers, researchers and students working in this field. They have to find the "optimal compromise" in keeping the YSZ TBC surface temperature below an upper temperature limit and at the same time keeping the MCrAlY BC and metallic Ni-based superalloy turbine component below another upper temperature limit.

For current state-of-the-art TBCs, the YSZ TBC surface temperature (T-ysz) shall not exceed $\sim 1300{ }^{\circ} \mathrm{C}$ at the same time not allowing the MCrAlY BC (T-bc) and substrate component (T-sub) temperatures to reach values above $\sim 1100{ }^{\circ} \mathrm{C}$ and $\sim 1000{ }^{\circ} \mathrm{C}$; respectively. The upper surface temperature limit for YSZ TBC of $\sim 1300{ }^{\circ} \mathrm{C}$ was established based on distinct YSZ degradations. They become exacerbated at temperatures higher than $\sim 1300{ }^{\circ} \mathrm{C}$ and are caused by: (i) YSZ delamination led by calcia-magnesia-alumina-silica (CMAS) glass deposits; as per Borom et al. (Ref 9)

(ii) YSZ phase transformations; as per Brandon and Taylor (Ref 10)

(iii) YSZ sintering; as per Thompson and Clyne (Ref 11)

The upper temperature limit of the MCrAlY $\mathrm{BC}$ of $\sim 1100{ }^{\circ} \mathrm{C}$ is based on the thickening of the $\mathrm{Al}_{2} \mathrm{O}_{3}$-based thermal grown oxide (TGO) layer (formed at the YSZ $\mathrm{TBC} / \mathrm{BC}$ interface), which is caused by the oxidation of the $\mathrm{BC}$ and is proportional to the operational temperatures. After a critical TGO layer thickness is reached, the stresses lead to the crack, failure and spallation of the YSZ TBC (which occurs at and/or alongside the TGO layer). As shown by Vaßen et al (Ref 12), when the APS YSZ TBCs are burner-rig cycled within a range of $1030-1100{ }^{\circ} \mathrm{C}$ for $\mathrm{BC}$ (i.e., T-bc), the thermal cycle lifetime of an APS TBC is drastically reduced when T-bc approaches $1100{ }^{\circ} \mathrm{C}$.

The upper temperature limit for the Ni-based superalloy substrate components ( $\mathrm{T}$-sub) is typically considered to be $\sim 1000^{\circ} \mathrm{C}$ and it is related to yield strength. The yield strength indicates the limit of elastic behavior and the beginning of plastic behavior of materials. Data on the yield strength values in function of temperature for different Ni-based polycrystalline superalloys employed in the hot-sections of gas turbine engines can be found in the literature (Ref 13). The yield strength values of these alloys at a T-sub of $\sim 1000{ }^{\circ} \mathrm{C}$ are rapidly approaching their respective plastic deformation zones.

A previous study spotlighted the thermal gradients obtained across a thermally sprayed APS YSZ TBC/substrate architecture (Ref 14). A thermal gradient laser-rig was used to create the temperature drop between the YSZ $\mathrm{TBC}$ and the substrate. $\mathrm{A} \mathrm{CO}_{2}$ laser heated the YSZ TBC surface, while an air jet was cooling the uncoated back-side of the substrate. By using this instrument, the thermal gradients can be created, evaluated and measured. In addition, this study also provided a summary of different thermal gradient values reported in the literature (based on burner-rig and laser-rig data) for APS YSZ TBCs.

It needs to be stressed that this temperature compromise mentioned above is also dependent on the TBC thickness and its thermal conductivity (TC) levels. Helminiak et al. (Ref 15) explored the concept of thermal resistance (Rtherm) for TBC systems; which is given by:

$R_{\text {therm }}=\frac{\text { thick }}{T C_{\text {ceramic top coat }}}\left(\frac{m^{2} K}{W}\right)$

where "thick" is the thickness and "TC" is the thermal conductivity of the ceramic top coat. The thermal resistance is a measure of the thermal insulating effectiveness of 
a TBC. It can be maximized by increasing the thickness of the ceramic top coat and/or by minimizing the thermal conductivity of the ceramic top coat. Evidently, the target is defined by trying to get the best compromise between the $\mathrm{BC}$ and substrate temperature and the TBC surface temperature. Since the heat intensities and cooling efficiencies of a turbine vary across the different component locations, this "optimal" compromise can be achieved by spraying the same YSZ TBC but manufactured at different thicknesses accordingly to the temperature reduction needs.

\section{Objectives}

This engineering paper has two major objectives that are (i) addressing TBC manufacturing efficiency issues and (ii) providing additional data on the thermal gradients within TBCs and metallic components. By addressing TBC manufacturing efficiency, the target was to deposit a conventional looking (porous) YSZ TBC using a high-enthalpy $150 \mathrm{~kW}$ APS torch $\left(\mathrm{N}_{2}\right.$-based plasma), at a powder feed rate of $100 \mathrm{~g} / \mathrm{min}$ and at the same time reaching a YSZ DE value of at least $60 \%$. Besides, this YSZ TBC needs to be porous of "conventional looking industrial quality". In other words, it needs to exhibit porosity levels within those typically accepted for porous TBCs of aerospace turbines (i.e., 10-20\%) and bond strength levels found within those reported in the literature for APS YSZ TBCs.

Regarding providing additional data on TBC thermal gradients, the same YSZ TBC described above was sprayed at two distinct sets of thickness: 400-500 $\mu \mathrm{m}$ and 900-1000 $\mu \mathrm{m}$. By employing a thermal gradient laser-rig, different thermal gradients were produced and reported in this manuscript. The aim was to determine the maximum temperature a porous YSZ APS TBC can be subjected while maintaining the temperature of the substrate temperature at values no higher than $\sim 1000{ }^{\circ} \mathrm{C}$. It is believed that these sets of results are of high importance to TBC designers, mainly regarding modelling and simulation.

\section{Experimental Procedure}

\section{TBC Manufacturing}

All TBCs produced for this study (including top and bond coats) were sprayed using the same high-enthalpy $150 \mathrm{~kW}$ APS torch (Axial III Plus, Northwest Mettech, Surrey, BC, Canada). The Axial III Plus is a smaller (length $15.5 \mathrm{~cm}$ and width $8.6 \mathrm{~cm}$ ) and $90^{\circ}$ version of the original Axial III torch. In fact, it is $\sim 50 \%$ shorter and $\sim 5 \%$ narrower than the original Axial III. Although smaller, it can use the same console, chiller, power supply, spray parameters and power levels of those of the original Axial III torch. The
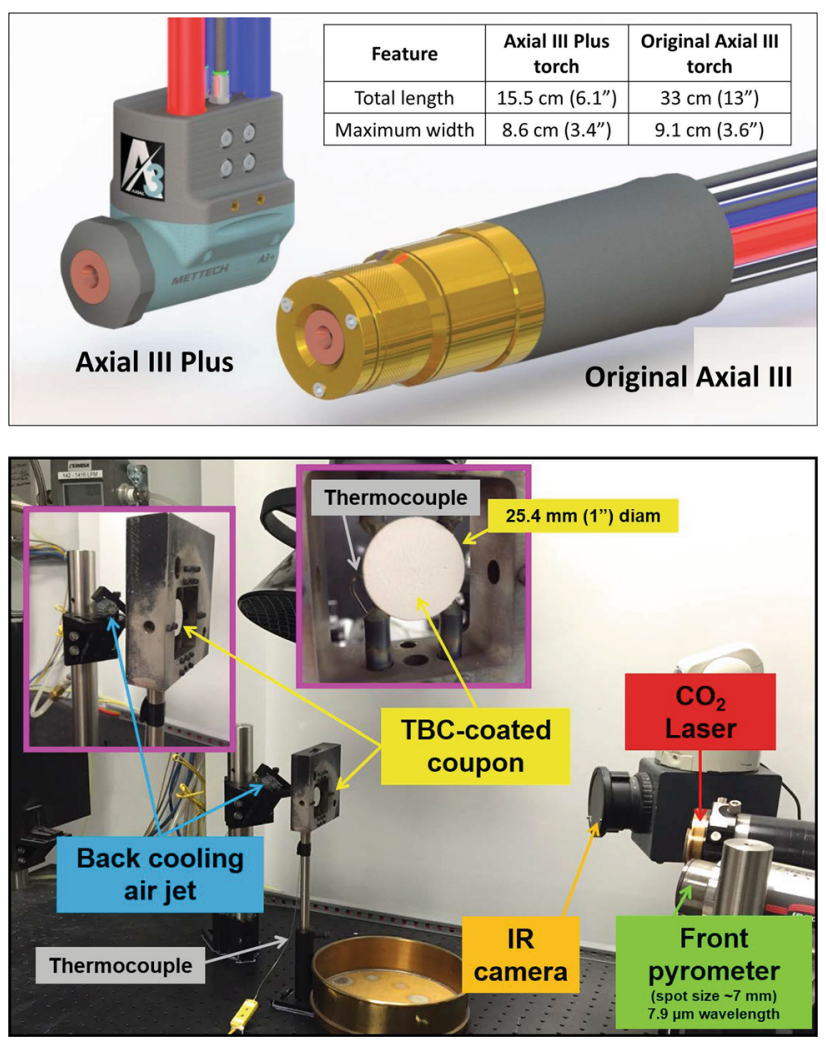

Fig. 1 Experimental procedure equipment: (a) the schematics of original Axial III and Axial III Plus torches and (b) the overall view of the NRC's thermal gradient laser-rig

schematics of original Axial III and Axial III Plus torches side by side can be seen in Fig. 1(a). Due to its $90^{\circ}$ configuration, the Axial III Plus can be potentially applied to spray coatings in internal diameters (IDs). In this study, the spray distance (SD) employed to spray both the MCrAlY $\mathrm{BC}$ and the YSZ top coat was $7.5 \mathrm{~cm}$. For this reason, based on the (i) torch length of $15.5 \mathrm{~cm}$, (ii) SD of $7.5 \mathrm{~cm}$ and (iii) assuming the need of having $2 \mathrm{~cm}$ safety gap; it can be presupposed that this TBC could be sprayed inside a minimum ID of $25 \mathrm{~cm}$ (10"). However, in this work the coatings were sprayed in outer diameter (OD) configuration.

For microstructural characterization and bond strength testing, the TBCs were manufactured on puck-shaped (25.4 $\mathrm{mm}$ diameter and $6.4 \mathrm{~mm}$ thick) low carbon steel substrates. The substrates were grit-blasted with white $\mathrm{Al}_{2} \mathrm{O}_{3}$ grit \#60 at 4.1 bar (60 psi) prior to BC spraying. The low carbon steel substrate roughness $\left(R_{a}\right)$ value (stylus profilometer) after grit-blasting was $3.2 \pm 0.2 \mu \mathrm{m}(n=10$ at a cut-off length $(\lambda c)$ of $2.5 \mathrm{~mm})$

For thermal gradient laser-rig testing, the TBCs were manufactured on puck-shaped $(25.4 \mathrm{~mm}$ diameter and 3.2 mm thick) Rene' N515 substrates. Before spraying, a 0.87$\mathrm{mm}$ hole was drilled at the mid-thickness of the substrate 
throughout its entire $25.4 \mathrm{~mm}$ diameter (for thermocouple insertion during thermal gradient testing). In addition, on the side where the TBCs were deposited, the edges were rounded up to minimize sharp-corner stresses that arise during coating deposition and thermal gradient testing. The substrates were grit-blasted with white $\mathrm{Al}_{2} \mathrm{O}_{3}$ grit \#24 at 2.8 bar (40 psi) prior to BC spraying. The Rene' N515 substrate roughness $\left(R_{a}\right)$ value (stylus profilometer) after grit-blasting was $5.0 \pm 0.3 \mu \mathrm{m}(n=10 @ \lambda \mathrm{c}=2.5 \mathrm{~mm})$. In order to improve the uniformity of the study, the spraying of the BC and YSZ top coat occurred at the respective same runs for both types of substrates.

The BC feedstock composition was the NiCoCrAlYHfSi (Amdry 386-4, Oerlikon Metco, Westbury, NY, USA). This powder displays a particle size distribution of $\mathrm{d}_{10}: 48 \mu \mathrm{m} ; \mathrm{d}_{50}: 59 \mu \mathrm{m} ; \mathrm{d}_{90}: 75 \mu \mathrm{m}$. The BC was sprayed using an $\mathrm{Ar} / \mathrm{N}_{2} / \mathrm{H}_{2}$ plasma composition at a $\mathrm{SD}$ of $7.5 \mathrm{~cm}$ using a carrousel fixture (sample tangential speed of $1.2 \mathrm{~m} /$ $\mathrm{s}$ and torch transverse speed of $5 \mathrm{~mm} / \mathrm{s}$ ). The BC thickness was $\sim 160 \mu \mathrm{m}$. The $\mathrm{BC}$ roughness $\left(R_{a}\right)$ value (stylus profilometer) was $13.31 \pm 1.26 \mu \mathrm{m}(\mathrm{n}=10 @ \lambda \mathrm{c}=2.5 \mathrm{~mm})$.

The top coat YSZ feedstock was $\mathrm{ZrO}_{2}-8$ wt. $\% \mathrm{Y}_{2} \mathrm{O}_{3}$ (204B-NS, Oerlikon Metco, Westbury, NY, USA). The powder displays a particle size distribution of $\mathrm{d}_{10}: 37 \mu \mathrm{m}$, $\mathrm{d}_{50}: 62 \mu \mathrm{m}$ and $\mathrm{d}_{90}: 84 \mu \mathrm{m}$. The YSZ was sprayed using an $\mathrm{N}_{2} / \mathrm{H}_{2}(75 \mathrm{vol} \% / 25 \mathrm{vol} \% @ 98 \mathrm{~kW}$ of power) plasma composition at a SD of $7.5 \mathrm{~cm}$ using a carrousel fixture (sample tangential speed of $2.4 \mathrm{~m} / \mathrm{s}$ and torch transverse speed of 10 $\mathrm{mm} / \mathrm{s}$ ). The exact same set of optimized spray parameters were used to deposit two YSZ TBCs of different thicknesses values: (i) $\sim 420 \mu \mathrm{m}$ and (ii) $\sim 930 \mu \mathrm{m}$. The roughness $\left(R_{a}\right)$ values (stylus profilometer) for the $\sim 420 \mu \mathrm{m}$-thick and $\sim 930 \mu \mathrm{m}$-thick YSZ TBCs were $12.55 \pm 1.17 \mu \mathrm{m}$ and $12.39 \pm 0.95 \mu \mathrm{m}(\mathrm{n}=10 @ \lambda \mathrm{c}=2.5$ $\mathrm{mm})$; respectively.

The YSZ deposition efficiency (DE) values were calculated by spraying YSZ onto grit-blasted Almen N strips (76.2 mm x $19.05 \mathrm{~mm} \times 0.79 \mathrm{~mm}$ ) without BC. The Almen $\mathrm{N}$ strips were placed together in the carrousel fixture along the other samples produced for this study. The DE was measured based on the weight of the strips before and after YSZ deposition, as well as, on the powder feed rate and on the total time the torch was over the strip during spraying.

During spraying, a vortex air jet fixture cooling and two overspray air jets mounted on the torch were employed together to limit the temperature of the samples during coating manufacturing. The coating surface temperature during spraying was monitored via an infra-red (IR) camera (FLIR A320), mounted in line-of-sight of the carrouselheld sample at $90^{\circ}$ angle from the plasma spray jet. Consequently, during deposition the torch never blocked the sight of the camera. The complete sets of spray parameters for this TBC architecture are considered as intellectual property (IP) of the National Research Council of Canada (NRC) and cannot be divulged. However, an overall summary of the spray parameters, including plasma gas combination, powder feed rate, plasma torch power, deposition rate (DR), deposition efficiency (DE) values can be found in Table 1 .

\section{YSZ TBC Density and Porosity Values}

The density value of the as-sprayed YSZ TBC $\left(d_{\mathrm{ysz}}\right)$ was measured via the Archimedes technique in water: $d_{\mathrm{ysz}}(\mathrm{g} /$ $\left.\mathrm{cm}^{3}\right)=\left(d_{\text {water }} \times m_{\text {dry }}\right) \div\left(m_{\text {wet }}-m_{\text {immersed }}\right)$; where $d_{\text {water }}$ is $1.00 \mathrm{~g} / \mathrm{cm}^{3}$ and $m$ is the YSZ free-stand mass in grams. A total of 3 free-standing YSZ coatings were used to determine the density values. A $\sim 930 \mu \mathrm{m}$-thick YSZ TBC (deposited together with tested samples) was deposited on grit-blasted puck-shaped $(25.4 \mathrm{~mm}$ diameter and $6.4 \mathrm{~mm}$ thick) low carbon steel substrates without BC. Subsequently free-standing YSZ coatings were obtained by placing the coupons in an acid bath $\left(45 \mathrm{vol} \% \mathrm{HNO}_{3}+\right.$ $45 \mathrm{vol} \% \mathrm{H}_{2} \mathrm{SO}_{4}+10$ vol. $\% \mathrm{H}_{2} \mathrm{O}$ ), which dissolved the metallic substrate. After substrate dissolution, the YSZ free-stands were washed in water and dried in a lab stove at $125^{\circ} \mathrm{C}$ for $2 \mathrm{~h}$.

The as-sprayed YSZ porosity value was estimated based on the ratio between the coating density (measured via Archimedes) with that of a fully dense bulk YSZ sample; i.e., $6.00 \mathrm{~g} / \mathrm{cm}^{3}$. Exemplifying, if a free-stand YSZ TBC density is $5.17 \mathrm{~g} / \mathrm{cm}^{3}$, and is then divided by the bulk density of the YSZ $\left(6.00 \mathrm{~g} / \mathrm{cm}^{3}\right)$ and multiplied by 100 ; this gives a value of 86.2. Consequently, the YSZ TBC density is $86.2 \%$ that of the fully dense bulk. Thereby, porosity value of the YSZ TBC is $13.8 \%$.

\section{Cross-sectional Microstructural Characterization}

In order to better preserve their real microstructures, the assprayed TBC samples were initially vacuum impregnated in epoxy resin and posteriorly ground/polished according to standard metallography procedures for TBCs. The crosssectional microstructural features of the TBCs were analyzed by scanning electron microscopy (SEM). In addition, the elemental composition of the MCrAlY BC was evaluated via energy dispersive $\mathrm{X}$-ray spectroscopy (EDX).

\section{X-ray Diffraction (XRD)}

$\mathrm{XRD}$ using $\mathrm{CuK} \alpha$ radiation was employed to evaluate the phase compositions of the as-sprayed YSZ TBCs. The $\mathrm{XRD} 2 \theta$ values ranged from $20^{\circ}$ to $80^{\circ}$ (scanning step size of $0.05^{\circ}$ and step time of $2.5 \mathrm{~s}$ ). 
Table 1 Overall summary of the spray parameters for BC and YSZ manufacturing via the Axial III Plus APS torch

\begin{tabular}{|c|c|c|c|c|c|c|c|c|}
\hline Coating type & $\begin{array}{l}\text { Plasma } \\
\text { gases }\end{array}$ & $\begin{array}{l}\text { Powder feed } \\
\text { rate } \\
(\mathrm{g} / \mathrm{min})\end{array}$ & $\begin{array}{l}\text { Plasma power } \\
\qquad(\mathrm{kW})\end{array}$ & $\begin{array}{l}\mathrm{SD} \\
(\mathrm{cm})\end{array}$ & $\begin{array}{c}\text { Maximum coating surface } \\
\text { temperature }\left({ }^{\circ} \mathrm{C}\right)\end{array}$ & $\begin{array}{c}\mathrm{DR} \\
(\mu \mathrm{m} / \text { pass })\end{array}$ & $\begin{array}{l}\mathrm{DE} \\
(\%)\end{array}$ & $\begin{array}{l}\text { Coating } \\
\text { thickness } \\
(\mu \mathrm{m})\end{array}$ \\
\hline $\begin{array}{l}\text { NiCoCrAlY }+\mathrm{HfSi} \\
\text { Amdry 386-4 }\end{array}$ & $\mathrm{Ar} / \mathrm{N}_{2} / \mathrm{H}_{2}$ & 50 & 71 & 7.5 & $\sim 550$ & $\sim 21$ & 55 & $\begin{array}{c}\sim 160 \\
(\mathrm{NRC} \\
\# 210812 \mathrm{~B} 2)\end{array}$ \\
\hline $\begin{array}{l}\mathrm{ZrO}_{2}-8 w t . \% \mathrm{Y}_{2} \mathrm{O}_{3} \\
\text { (YSZ) } \\
204 \mathrm{~B}-\mathrm{NS}\end{array}$ & $\mathrm{N}_{2} / \mathrm{H}_{2}$ & 100 & 98 & 7.5 & $\sim 600$ & $\sim 23$ & 70 & $\begin{array}{c}\sim 420 \\
(\mathrm{NRC} \\
\# 210817 \mathrm{~B} 1) \\
\sim 930 \\
(\mathrm{NRC} \\
\# 210817 \mathrm{~B} 3)\end{array}$ \\
\hline
\end{tabular}

\section{Bond Strength}

The as-sprayed bond strength of the two TBCs produced in this study were measured using the ASTM C633 standard (Ref 16). In ASTM C633 standard, the coating and respective substrate $(25.4 \mathrm{~mm}$ diameter) are bonded to loading fixtures using an epoxy glue; the full assembly is then subjected to a tensile load that is perpendicular to the plane of the coating. The epoxy glue FM1000 (Couch Sales LLC, Hilton Head Island, SC, USA) was used (it requires $1.5 \mathrm{~h}$ at $180{ }^{\circ} \mathrm{C}$ for curing) to assemble the testing set-up. The FM1000 glue was chosen in order to prevent impregnation of the ceramic coating and influence on the adhesion result. An Instron 5582 universal testing machine (Burlington, ON, Canada) was used with a dynamic load up to $100 \mathrm{kN}$ at a constant speed of $1.2 \mathrm{~mm} / \mathrm{min}$. A reference dummy sample used to verify the glue performance; which yielded a strength value of $77 \mathrm{MPa}$.

\section{YSZ Elastic Modulus Via Instrumented Indentation Testing}

Instrumented indention testing (G200, Agilent Technologies, Santa Clara, CA, USA) was employed to measure the elastic modulus values of the as-sprayed YSZ TBCs. This technique was developed by Oliver and Pharr (Ref 17), where the mechanical properties of materials can be determined directly from the indentation load and indentation displacement using high-resolution testing equipment. The system employed a Berkovich indenter and was performed by using these main equipment set-up inputs: YSZ Poisson's ratio estimated at 0.25 , time to load $15 \mathrm{~s}$, maximum indentation load of $50 \mathrm{gf}$ and hold time at maximum indentation load of $10 \mathrm{~s}$.

The elastic modulus values were measured over the polished cross sections of the coatings prepared for SEM evaluation (as described above). For each YSZ TBC, a total of 3 series zones were tested: (i) next to BC ( $\sim 50 \mu \mathrm{m}$ from $\mathrm{BC}$ ), (ii) mid-coating thickness and (iii) next to outer surface ( $\sim 50 \mu \mathrm{m}$ from epoxy resin). A total of 25 indentations were taken for each single zone; i.e., each YSZ TBC was indented 75 times.

Before testing the samples, the calibration of the equipment was double-checked with a fused silica $\left(\mathrm{SiO}_{2}\right)$ standard, using the same indentation set-up inputs. A total of 5 indentations were generated before the TBCs were probed. An average elastic modulus value of $71.8 \pm$ $0.3 \mathrm{GPa}$ was obtained, which is close to the results reported by Oliver and Pharr for $\mathrm{SiO}_{2}$, i.e., $70 \mathrm{GPa}$ (Ref 17).

\section{Thermal Gradient Laser-Rig Testing}

The main characteristics of NRC's thermal gradient laserrig has been previously described elsewhere (Ref 14). It is based on a $3-\mathrm{kW} \mathrm{CO}_{2}$ laser, which produces a constant laser beam (10.6 $\mu \mathrm{m}$ wavelength) over the YSZ TBC top coat. The rig is set to create a laser spot size of about $25 \mathrm{~mm}$ (1") in diameter, in order to fit the dimensions of the puck-shaped coupon. A compressed air jet at room temperature (RT) cools the un-coated backside of the substrate in order to generate the thermal gradient across the TBC/substrate profile. The rig is closed-loop computercontrolled; therefore, the temperature of the YSZ top coat (T-ysz) and the temperature of the substrate (T-sub) are continuously monitored during the tests. The overall image of the laser-rig is found in Fig. 1(b).

The temperature of the YSZ top coat (T-ysz) was monitored using a one-color 7.9- $\mu \mathrm{m}$ wavelength pyrometer with a spot size of $\sim 7 \mathrm{~mm}$ at the center of the sample. An infrared (IR) camera (7.5-14 $\mu \mathrm{m}$ spectral range) coupled with a $\mathrm{CO}_{2}$ notch filter at $8 \mu \mathrm{m}$ was also employed to measure the overall distribution of temperature on the 
surface of the YSZ top coat. The IR camera is used as a guide to guarantee that a uniform laser beam is right centered on surface of the TBC. The emissivity value for the YSZ was measured and set as 0.96 for a IR wavelength of $7.9 \mu \mathrm{m}$; which is similar to the 0.94 value reported by González-Fernández et al. (Ref 18) for YSZ at this wavelength.

The substrate temperature (T-sub) was measured at the coupon center by using a thermocouple (Omega, KMQIN032U-12, Nicrosil/Nisil, Norwalk, CT, USA) that was inserted into a hole drilled at the mid-thickness position of the $25.4 \mathrm{~mm}$ diameter puck-shaped substrate (Fig. 1b). For this reason, as the substrate is $3.2 \mathrm{~mm}$-thick, the T-sub was measured at a position of $\sim 1.6 \mathrm{~mm}$ beneath the $\mathrm{BC} / \mathrm{sub}$ strate interface.

For creating the temperature profiles $(\Delta \mathrm{Ts})$ via the laserrig along the thicknesses of the TBC/substrate systems, initially the RT cooling air jet on the un-coated backside of the substrate was set to be constant at $\sim 430 \mathrm{lpm}$. Therefore, the cooling conditions were identical to all TBCcoated samples during this study. For this reason, to generate the distinct $\Delta \mathrm{Ts}$, the laser power was adjusted and set to keep the YSZ TBC surface temperature (T-ysz) constant at pre-set values, e.g., $1100,1200,1300{ }^{\circ} \mathrm{C}$ (i.e., $100{ }^{\circ} \mathrm{C}$ steps) and so on. Thus, the higher the T-ysz pre-set, the higher the laser power necessary to achieve the T-ysz preset value. The T-ysz was increased until the temperature of the substrate (T-sub) reached around $1000{ }^{\circ} \mathrm{C}$; which is typically considered to be the highest limit of temperature operation for static gas turbine components (e.g., combustion chamber).

The same as-sprayed sample of each YSZ TBC system produced in this work $(\sim 420 \mu \mathrm{m}$-thick and $\sim 930 \mu \mathrm{m}$ thick) was used in these experiments establish the thermal gradient and measure the $\Delta \mathrm{Ts}$. Each single set of $\Delta \mathrm{Ts}$ were generated for nearly $30 \mathrm{~min}$. This amount of time was chosen as to be a compromise between (i) having a "long enough" stable period to measure the $\Delta \mathrm{T}$ of an as-sprayed $\mathrm{TBC}$ and (ii) but at the same time not having a "long enough" high temperature exposure to minimize TBC sintering effects.

\section{Results and Discussion}

\section{APS NiCoCrAIY + HfSi Bond Coat}

Figure 2 shows the SEM cross-sectional micrograph of the NiCoCrAlY+HfSi BC sprayed via the Axial III Plus (without the YSZ TBC). The maximum BC surface temperature reached during spraying was $\sim 550{ }^{\circ} \mathrm{C}$ (monitored using an infra-red camera). The chemical composition of the $\mathrm{BC}$ was determined via EDX within the rectangular

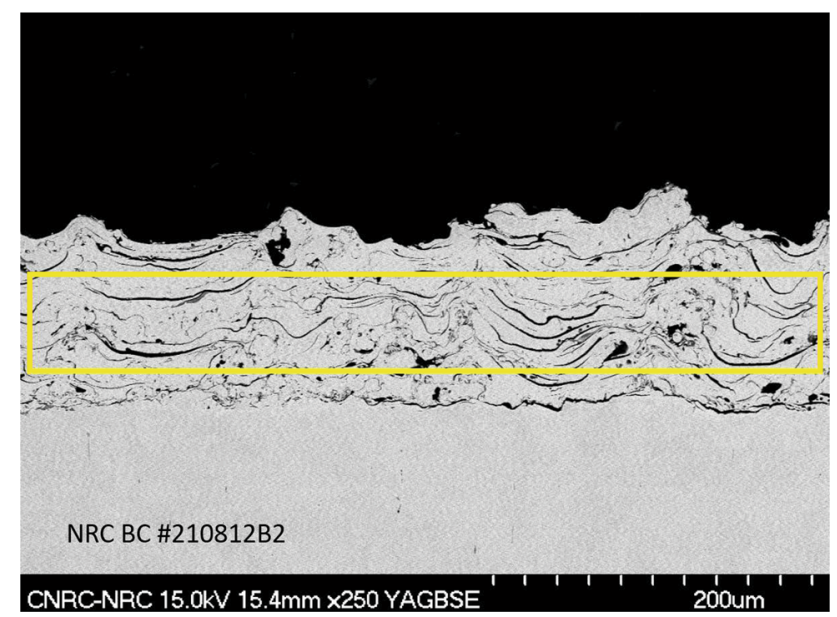

Fig. 2 As-sprayed cross-sectional SEM picture of the NiCoCrA1Y+HfSi BC employed in this study - the rectangular box identifies the area where EDX mapping was performed (Table 2)

area $(\sim 500 \mu \mathrm{m} \times \sim 55 \mu \mathrm{m})$ featured over the $\mathrm{BC}$ and the results shown in Table 2. It is possible to observe that the chemical composition of the as-sprayed $\mathrm{BC}$ is found within the range of that of the MCrAlY powder feedstock (provided by the powder manufacturer). The amount oxygen in the as-sprayed BC is $\sim 1.4 \mathrm{wt} . \%$. This amount is within the range of those exhibited by NiCoCrAlY+HfSi BCs when deposited via APS at the NRC (i.e., $\sim 0.7-1.5 \mathrm{wt} . \%$ ) and when measured by the same technique.

The BC $\mathrm{R}_{\mathrm{a}}$ value was $13.31 \pm 1.26 \mu \mathrm{m}(n=10 @ \lambda \mathrm{c}=$ $2.5 \mathrm{~mm}$ ). According to Feuerstein et al. (Ref 1), in order to provide optimum adherence for a ceramic TBC, a surface roughness $\left(R_{a}\right)$ of the MCrAlY BC of at least approximately $10 \mu \mathrm{m}$ is desirable so as to mechanically anchor the layers together. Typical $R_{a}$ values of thermally sprayed MCrAlY BCs are within the ranges 7-10 $\mu \mathrm{m}$ as reported by Schmidt et al. (Ref 19) and by Eriksson et al. (Ref 20), as well as, $10-13 \mu \mathrm{m}$ as reported by Haynes et al. (Ref 21$)$. Consequently, the $\mathrm{R}_{\mathrm{a}}$ value reported for the $\mathrm{BC}$ produced in this work is located in the upper range of the values reported in the literature and above the minimum $R_{a}$ value recommended by Feuerstein et al. (Ref 1).

Schmidt et al (Ref 19), Eriksson et al. (Ref 20) and Bossmann et al. (Ref 22) demonstrated that the higher BC roughness values lead to a longer lifetime performance of YSZ APS TBCs when subjected to thermal cycling. Although the YSZ TBC cracking, failure and spallation occurs at the TGO region and a critical TGO thickness is needed for the spallation of the YSZ TBC, the critical value of TGO thickness depends on the roughness value of the $\mathrm{BC}$ (i.e.; the rougher the $\mathrm{BC}$, the thicker the $\mathrm{TGO}$ critical thickness). Understanding the mechanisms of failure of TBCs is a complex issue. Besides characteristics like BC surface roughness and TGO layer thickening; factors like 
Table 2 Chemical composition of the MCrAlY feedstock and as-sprayed BC

\begin{tabular}{lcccccccc}
\hline \multicolumn{1}{c}{ Material } & $\begin{array}{c}\mathrm{Ni} \\
(\text { wt.\%) }\end{array}$ & $\begin{array}{c}\mathrm{Co} \\
(\text { wt.\%) }\end{array}$ & $\begin{array}{c}\mathrm{Cr} \\
(\text { wt.\%) }\end{array}$ & $\begin{array}{c}\mathrm{Al} \\
\text { (wt.\%) }\end{array}$ & $\begin{array}{c}\mathrm{Y} \\
\text { (wt.\%) }\end{array}$ & $\begin{array}{c}\mathrm{Hf} \\
\text { (wt.\%) }\end{array}$ & $\begin{array}{c}\mathrm{Si} \\
\text { (wt.\%) }\end{array}$ & $\begin{array}{c}\mathrm{O} \\
\text { (wt.\%) }\end{array}$ \\
\hline $\begin{array}{l}\text { Amdry 386-4 NiCoCrAlY+HfSi powder } \\
\text { (manufacturer certificate) }\end{array}$ & $\mathrm{Bal}$ & $19-26$ & $14-21$ & $11-14$ & $0.2-0.8$ & $0.1-0.5$ & $0.1-0.7$ & $\ldots$ \\
\begin{tabular}{l} 
Axial III Plus NiCoCrAlY+HfSi BC \\
\hline
\end{tabular} & 47.49 & 21.52 & 17.04 & 11.22 & 0.52 & 0.37 & 0.39 & 1.44 \\
\hline
\end{tabular}

BC composition, BC spraying (e.g., BC as-sprayed oxidation), operating temperature, cycles, mechanical loading, stresses, phase transformations and atomic diffusion play important roles in the outcome. Nonetheless, in a "very simplistic way", it is known that the crack path that leads to the YSZ TBC spallation originates and propagates at and/or alongside the TGO layer (which forms over the BC roughness). For this reason (for the same $\mathrm{BC}$ composition and deposition method) usually the rougher the surface of the $\mathrm{BC}$, the longer the critical path for crack propagation to promote YSZ TBC spallation. As a consequence, typically rougher BC surfaces tend to translate into longer thermal cycle lives for APS YZ TBCs. Therefore, the high $\mathrm{R}_{\mathrm{a}}$ value of $\sim 13 \mu \mathrm{m}$ reported for the BC manufactured in this work can be preliminary considered as "a desirable target"; but further thermal cycle testing is necessary to confirm this hypothesis.

By looking at Table 1, one can notice that the BC powder was sprayed at $50 \mathrm{~g} / \mathrm{min}$ of powder feed rate and its DE value was $55 \%$ when sprayed at $71 \mathrm{~kW}$. It is difficult to find information on the open literature about the DEs of MCrAlY BCs deposited via APS. However, based on NRC's own experience, the combination of the powder feed rate employed (50 g/min) and resulting DE $(55 \%)$ is considered to be "good" for a BC manufactured via APS. Of course, this DE value could be easily augmented by further increasing the plasma torch power (for example). On the other hand, the $\mathrm{BC}$ can become highly oxidized. The production of BCs via APS needs to find the "right balance" of obtaining at least "acceptable" values of powder feed rate, DE, as-sprayed $B C R_{a}$ and oxidation levels.

\section{APS YSZ TBC Architectures: Microstructure}

As described in Table 1, the YSZ power feed rate and its DE value were $100 \mathrm{~g} / \mathrm{min}$ and $70 \%$, respectively. These can be considered "very high values" and show the effectiveness of a $\mathrm{N}_{2}$-based high-enthalpy APS torch to spray large amounts of YSZ and still obtaining an impressive DE level. It is important to point out that the majority of the porous APS YSZ TBC manufacturing being done today is performed by "legacy" torches, employing
$\mathrm{Ar}-\mathrm{H}_{2}$ plasmas, where the YSZ powder is typically sprayed at $60 \mathrm{~g} / \mathrm{min}$ or lower and the DE values are about $40 \%$ or below.

Nonetheless, it needs to be stated that superior DE levels and powder feed rates do not necessarily yield desired results. In fact, it is the contrary; they will tend to increase even further the stresses that occur during thermal spray deposition, which can lead to unwanted segmentation cracking, inter-pass delamination and reduced bond strength. For this reason, observing the microstructures is of paramount importance.

Figure 3 shows the SEM cross-sectional micrograph of the two full architecture TBCs manufactured via the Axial III Plus for this work: (i) $\sim 420 \mu \mathrm{m}$-thick YSZ TBC (Fig. 3a) and (ii) $\sim 930 \mu \mathrm{m}$-thick YSZ TBC (Fig. 3b). It is important to remember that both YSZ TBCs (i) were deposited on the same $\sim 160 \mu$ m-thick BC and (ii) sprayed using the same set of spray parameters (as per Table 1), i.e., only the YSZ thickness changes. At the YSZ DR of $\sim 23$ $\mu \mathrm{m} /$ pass, a total of 18 and 40 torch passes were employed to deposit the $\sim 420 \mu \mathrm{m}$-thick and $\sim 930 \mu \mathrm{m}$-thick YSZ TBCs; respectively. The maximum YSZ surface temperature (monitored using an infra-red camera) initially started to increase with each single torch pass (as expected); but stabilized at $\sim 600{ }^{\circ} \mathrm{C}$ after about 8-9 torch passes for both YSZ top coats. Consequently, a sample temperature stabilization was reached during spraying. This sample temperature stabilization most likely influenced the mechanical properties of TBCs, such as bond strength and elastic modulus values (to be discussed in the next paragraphs).

By looking at Fig. 3, it is possible to observe that both YSZ TBCs exhibit a conventional porous microstructure. It is noticed the presence of interlamellar boundaries, globular voids and microcracks; which are the result from previously molten and semi-molten YSZ particles that flattened, overlapped and re-solidified into an assembly of lamellas during spraying. There are no major cracking segmentation, horizontal inter-layer delamination or adhesion gaps at the YSZ/BC interface. This is an important result. It shows that under controlled conditions of spraying (e.g., spray parameters, torch/substrate relative motion and maximum coating temperature during spraying), superior yield TBC manufacturing can be performed without 

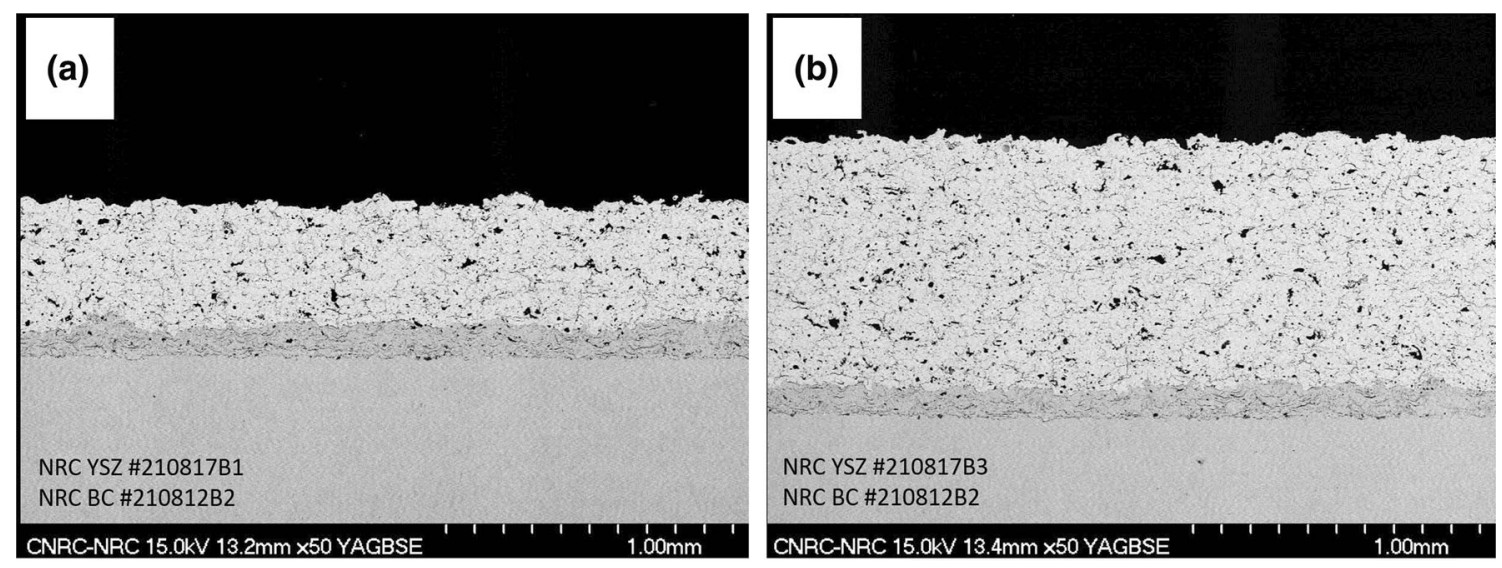

Fig. 3 As-sprayed cross-sectional SEM pictures of the two APS TBC architectures manufactured for this study: (a) 420 $\mu$ m-thick YSZ TBC and (b) $\sim 930 \mu \mathrm{m}$-thick YSZ TBC

Table 3 As-sprayed bond strength values of TBCs manufactured in this study and complementary data

\begin{tabular}{|c|c|c|c|c|c|c|c|}
\hline TBC sample & $\begin{array}{l}\text { Grit-blasted } \\
\text { substrate } \\
\mathrm{R}_{\mathrm{a}}(\mu \mathrm{m}) \\
\mathrm{n}=10 \\
\lambda \mathrm{c}=2.5 \mathrm{~mm}\end{array}$ & $\begin{array}{c}\text { BC thick } \\
(\mu \mathrm{m})\end{array}$ & $\begin{array}{c}\mathrm{BC} \\
\mathrm{R}_{\mathrm{a}}(\mu \mathrm{m}) \\
n=10 \\
\lambda c=2.5 \mathrm{~mm}\end{array}$ & $\begin{array}{c}\text { YSZ density } \\
(\%) \\
n=3\end{array}$ & $\begin{array}{c}\text { YSZ porosity } \\
(\%) \\
n=3\end{array}$ & $\begin{array}{l}\text { YSZ thick } \\
\qquad(\mu \mathrm{m})\end{array}$ & $\begin{array}{c}\text { Bond strength (MPa) } \\
n=5\end{array}$ \\
\hline $\begin{array}{l}\sim 420 \mu \mathrm{m} \text {-thick YSZ } \\
(\mathrm{NRC} \# 210817 \mathrm{~B} 1)\end{array}$ & $3.2 \pm 0.2$ & $\sim 160$ & $13.31 \pm 1.26$ & $5.15 \pm 1.26$ & $14.2 \pm 0.5$ & $\sim 420$ & $13.0 \pm 1.3$ \\
\hline $\begin{array}{l}\sim 930 \mu \mathrm{m} \text {-thick YSZ } \\
(\mathrm{NRC} \# 210817 \mathrm{~B} 3)\end{array}$ & & & & & & $\sim 930$ & $11.6 \pm 1.3$ \\
\hline
\end{tabular}

producing unwanted defects into the TBC microstructure. The as-sprayed density and porosity values of the YSZ TBC are $\sim 5.15 \mathrm{~g} / \mathrm{cm}^{3}$ and $\sim 14 \%$, respectively (Table 3 ). Therefore, this APS YSZ TBC has a porosity level in the range of $10-20 \%$, which is accepted for a porous TBC.

As a final remark, it needs to be stressed that APS YSZ TBCs exhibiting thickness around $1000 \mu \mathrm{m}$ (just like the one of this work) or even thicker are nothing new. They have been successfully applied in the industry, mainly for industrial gas turbines (IGTs) for many years. What this work wants to bring attention is the fact that these conventional porous TBCs can be manufactured not only at high powder feed rates, but also at high DE levels.

\section{APS YSZ TBC Architectures: As-Sprayed Bond Strength}

Bond strength testing is a very important complement feature to the microstructural characterization described in the previous session. As discussed, both YSZ top coats exhibited conventional porous microstructures and no major defects (Fig. 3). They were sprayed at $100 \mathrm{~g} / \mathrm{min}$ and the $\mathrm{DE}$ value is $70 \%$. These are coveted very high values. However, they may cause an over increase of residual stress levels, which could lead to low TBC adhesion values (mainly for the thicker $\sim 930 \mu \mathrm{m}$-YSZ TBC) and perhaps a "weak" performance during thermal cycling.

As an example, Vaßen et al. (Ref 23) produced YSZ TBCs via APS under different YSZ powder feed rates: 4.4, 9.1, 36.4 and $54.7 \mathrm{~g} / \mathrm{min}$. All TBCs were porous (12-15\%) and subjected to burner-rig testing under similar thermal gradient conditions. There was an increase of $\sim 20 \%$ in the number of cycles to failure for the TBCs produced from 4.4 to $9.1 \mathrm{~g} / \mathrm{min}$; which was the best performing. On the other hand, from 9.1 to $54.7 \mathrm{~g} / \mathrm{min}$, there was a reduction of $\sim 86 \%$ in the number of cycles to failure; which is considerably negative. Therefore, one may claim that elevated powder feed rates over $50 \mathrm{~g} / \mathrm{min}$ are inherently negative. However, the YSZ deposited at $9.1 \mathrm{~g} / \mathrm{min}$ (best performing) exhibited a DR of $\sim 7 \mu \mathrm{m} /$ pass; whereas that of the $54.7 \mathrm{~g} / \mathrm{min}$ YSZ (worst performing) was $\sim 31 \mu \mathrm{m} / \mathrm{pass}$; i.e., 4.4X higher. Consequently, it can be hypothesized that the enhanced powder feed rate was not necessarily the main responsible for the outcome, but rather the thicker DR 

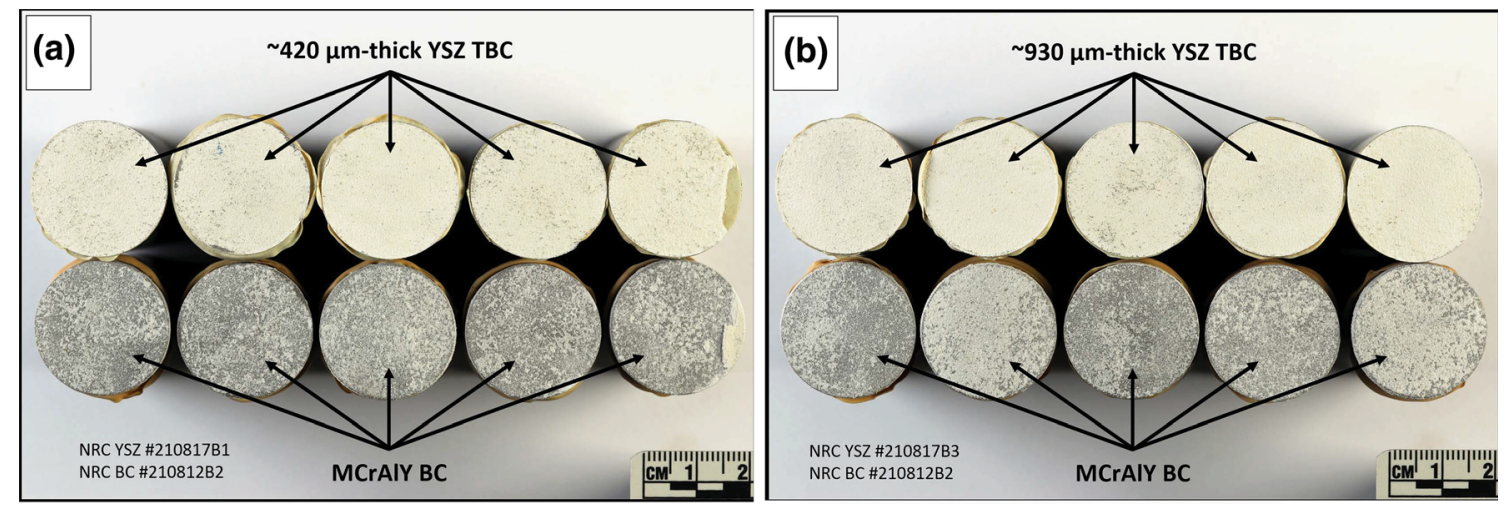

Fig. 4 Snap-shots of the fracture surfaces after bond strength (ASTM C633) testing for the two APS TBC architectures: (a) 420 $\mu \mathrm{m}$-thick YSZ TBC and (b) $\sim 930 \mu \mathrm{m}$-thick YSZ TBC

(i.e., increased residual stress effects). For this reason, when spraying YSZ at powder feed rates of $\geq 50 \mathrm{~g} / \mathrm{min}$, it is important to adjust the relative speed of the substrate surface and torch in order to avoid maximizing DR levels.

Thus, although the TBCs manufactured in this work do not exhibit unwanted defects (Fig. 3), to double-check if they were not "weakened" by residual stress effects, measuring their bond strength values is key to validate the microstructural results. The as-sprayed bond strength (ASTM C633) results and complementary data of both TBC manufactured for this study are found in Table 3 . Briefly, the bond strength for the $\sim 420 \mu \mathrm{m}$-thick TBC is $\sim 13.0 \mathrm{MPa}$, whereas that of the $\sim 930 \mu \mathrm{m}$-thick TBC is $\sim 11.6 \mathrm{MPa}$. This is considered as an interesting result. Despite the fact that one YSZ TBC is twice thicker than the other, the drop of bond strength intensity for the thicker $\sim 930 \mu \mathrm{m}$ YSZ TBC is just $11 \%$.

To better understand this small drop of TBC bonding, it is important to look at the data of Table 1. Initially, one needs to remember that both YSZs were sprayed over the same APS BC. As previously described, the maximum coating surface temperature during spraying grew in time with each single torch pass; however, it stabilized at $\sim 600{ }^{\circ} \mathrm{C}$ for both YSZ top coats after approximately 8-9 torch passes. In addition, the DR values were the nearly identical ( $\sim 23 \mu \mathrm{m} /$ pass) for both YSZ TBCs. The only major difference during spraying was the additional the number of torch passes required to spray the thicker YSZ TBC; i.e., 18 ( $\sim 20 \mu$ m-thick YSZ) versus 40 torch ( $\sim 930 \mu \mathrm{m}$-thick YSZ) passes.

To complement the discussion, the snap-shots of the fracture surfaces of tested samples are shown in Fig. 4 and also help to understand this issue. First of all, it is possible to notice that for both $\mathrm{TBCs}$ the $\mathrm{BC}$ remained adhered to the substrate. In addition, all TBC samples exhibited mixed bond strength failure, i.e., a combination of adhesive (YSZ/ $\mathrm{BC}$ interface) and cohesive (within YSZ) failures.
However, for the $\sim 420 \mu \mathrm{m}$-thick TBC, the failure was more adhesive; i.e., concentrated at the YSZ/BC interface. This conclusion is obtained by seeing the fracture surfaces on the substrate side (Fig 4a). The area amount of BC exposed (grey zone-YSZ/BC adhesive failure) is larger than that of the YSZ (white zone - YSZ cohesive failure). For the $\sim 930 \mu \mathrm{m}$-thick TBC, the amount of white area (YSZ cohesive failure) on the substrate side (Fig. 4b) becomes more evident, but the overall mixed failure characteristic is still similar to that of Fig. 4(a). For this reason, the small variation of macrostructural features of the fracture surfaces between both TBCs also help to understand the small drop of bond strength of the thicker coating.

The elastic modulus values of both YSZ TBCs measured via instrumented indentation can also shine a light on this subject. As described in "Thermal gradient laser-rig testing" section, for each YSZ TBC, a total of 3 series zones were tested: (i) next to $\mathrm{BC}$ ( $\sim 50 \mu \mathrm{m}$ from $\mathrm{BC})$, (ii) midcoating thickness and (iii) next to outer surface $(\sim 50 \mu \mathrm{m}$ from epoxy resin). A total of 25 indentations were taken for each single zone; i.e., each YSZ TBC was indented 75 times. These elastic modulus measurements can be found in Fig. 5. Essentially, the average and standard deviation values for both coatings, measured at the same equivalent zones, do not show a significant variation. The analysis of variance (ANOVA) confirmed that for each individual YSZ TBC, at the 0.01 level (i.e., $99 \%$ ), the population means are not significantly different (for each indentation zone). In simple words, it is not observed a noticeable gradient or variation of elastic modulus values for both coatings and they are relatively uniform across the coating thickness, not mattering if the YSZ TBC thickness is $\sim 420$ or $\sim 930 \mu \mathrm{m}$. As previously stated, the DR values were the nearly identical ( $\sim 23 \mu \mathrm{m} /$ pass) for both YSZ TBCs. In addition, the maximum coating surface temperature during deposition increased in time with each single torch pass; however, it 


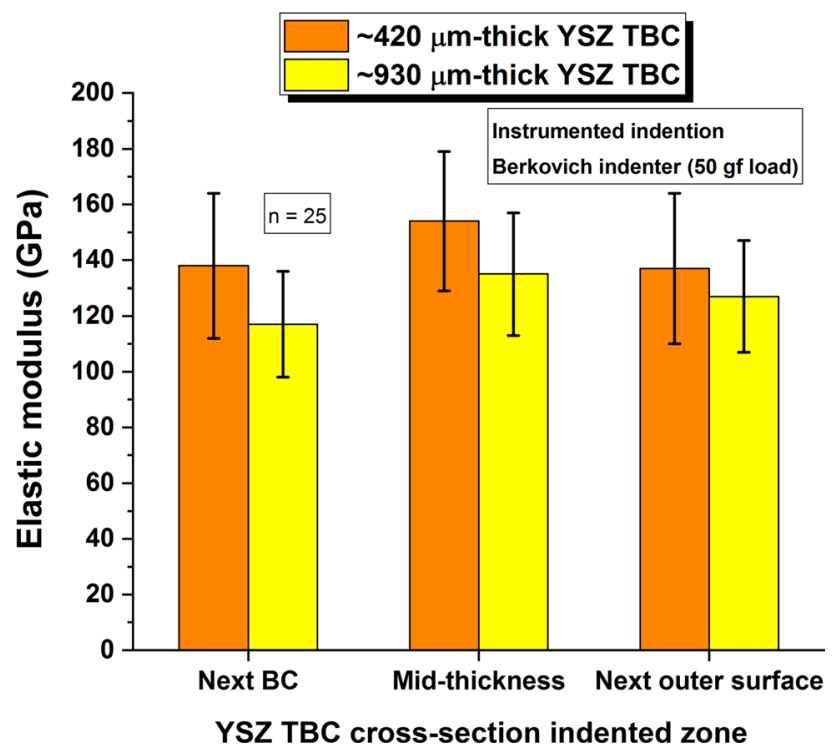

Fig. 5 Cross section elastic modulus values determined via instrumental indentation for both APS YSZ TBCs

never went above $\sim 600{ }^{\circ} \mathrm{C}$ for both YSZ top coats during spraying after 8-9 passes. Consequently, temperature distribution of the samples plateaued and stabilized during processing. Most likely these elements contributed to the uniformity elastic modulus results shown in Fig. 5; which in turn also help to explain (i) the low difference of bond strength between both TBCs (Table 3), (ii) their same failure mode (iii) and similar fracture surfaces (Fig. 4).

It is important to stress that Shinde et al. (Ref 24) also observed a similar behavior. It was reported the progression of the elastic modulus values (in-situ beam curvature method) along the thickness for a conventional porous APS YSZ TBC. Just like what was observed in this work, the maximum surface temperature of the TBC started to increase with the number of torch passes, but it stabilized at $\sim 550{ }^{\circ} \mathrm{C}$ after the initial 6-7 passes (of a total of 20+ passes). Within a range from approximately 100 to $700 \mu \mathrm{m}$, the conventional porous YSZ exhibited nearly constant elastic modulus values over all thicknesses $(\sim 50$ $60 \mathrm{GPa})$.

Another important point to be considered is the comparison of the bond strength values reported in this manuscript with those reported in the literature for porous and dense-vertically-cracked (DVC) APS YSZ TBCs. In simple words, it is necessary to know if the bond strength results reported in this manuscript are "good". Table 4 displays literature values for as-sprayed porous and DVC YSZ TBCs, based on the results of Guerreiro et al. (Ref 5), Smith et al. (Ref 25), Curry et al. (Ref 26), Lee et al. (Ref 27) and Myoung et al. (Ref 28). It needs to be stressed that just like in this work, these bond strength values were also determined via the ASTM C633 method. Overall, APS
YSZ TBCs are exhibiting bond strength levels ranging from $\sim 3$ to $\sim 15 \mathrm{MPa}$ within a wide variation of thicknesses $(\sim 400-2000 \mu \mathrm{m})$ and porosity $(\sim 3-23 \%)$ values. However, when the TBCs thicker than $\sim 1000 \mu \mathrm{m}$ are not considered (independently of porosity content); the bond strength values are found within the $\sim 7-15 \mathrm{MPa}$ range (Table 4). For this reason, it can be stated that the bond strength levels of the TBCs manufactured this study (i.e.; 11.6-13 MPa) are within the upper range of the values of those reported in the literature; which is a "good" result. As an industrial application curiosity, Smith et al. (Ref 25) reported that the lower bond strength acceptance limit for an industrial APS YSZ TBC exhibiting 10-15\% porosity would be 7.6 MPa. Therefore, both coatings sprayed in this study would far exceed the minimum bond strength requirements for a TBC in this case.

As this manuscript deals with YSZ spraying at high powder feed rates using a high-enthalpy plasma torch, it is interesting to further mention the works of Curry et al. (Ref 26), Lee et al. (Ref 27) and Myoung et al. (Ref 28); which also dealt with the same subject. Curry et al. (Ref 26) sprayed two YSZ powders at $280 \mathrm{~g} / \mathrm{min}$ using the highenthalpy 100HE APS torch (Progressive Surface, Grand Rapids, MI, USA). YSZ DE values ranging from $\sim 40-$ $52 \%$ were reported, and the porosity, thickness and bond strength values of these TBCs are found in Table 4. From these sets of data one can realize that YSZ powders can be sprayed at $280 \mathrm{~g} / \mathrm{min}$ and respective TBCs still exhibiting porosity levels acceptable for IGTs (i.e., 20-30\%) and bond strength values within the $\sim 7-15 \mathrm{MPa}$ range can be produced. Nonetheless, this elevated powder feed rate of 280 $\mathrm{g} / \mathrm{min}$ most likely limited the YSZ DE levels to $52 \%$. The YSZ TBCs of Lee et al. (Ref 27) listed in Table 4 were sprayed at $100 \mathrm{~g} / \mathrm{min}$ using the legacy torch $9 \mathrm{MB}\left(\mathrm{Ar} / \mathrm{H}_{2}\right.$ plasma) and the cascade torch TriplexPro (Ar/He plasma), both from the same company (Oerlikon Metco, Westbury, NY, USA). Unfortunately the YSZ DE values were not reported by the authors. The YSZ TBCs of Myoung et al. (Ref 28), also shown in Table 4, were also sprayed at 100 $\mathrm{g} / \mathrm{min}$ using the TriplexPro (Ar/He plasma). Here, again the YSZ DE values were not reported.

\section{APS YSZ TBC Architectures: XRD Phase Composition}

Figure 6 shows the XRD diffraction patterns of the YSZ powder feedstock and both as-sprayed YSZ TBCs. To analyze the XRD spectra of YSZ, it is generally easier to split the patterns into two zones, i.e., $2 \theta$ from $\sim 27.5$ to $32.5^{\circ}$ (Fig. 6a) and from $\sim 72$ to $76^{\circ}$ (Fig. 6b). By looking at Fig. 6(a) one wants to know if the presence of the unwanted monoclinic $(m)$ phase of YSZ is observed in the powder and as-sprayed TBCs. The $m$-YSZ phase is 
Table 4 As-sprayed bond strength values (ASTM C633) and complementary data for different APS YSZ TBCs reported in the literature

\begin{tabular}{llccclc}
\hline YSZ TBC type & $\begin{array}{c}\text { BC Ra } \\
(\mu \mathrm{m})\end{array}$ & YSZ porosity (\%) & YSZ thickness $(\mu \mathrm{m})$ & $\begin{array}{c}\text { Bond strength (MPa) } \\
n=3-5\end{array}$ & Epoxy glue & Reference \\
\hline Porous & $\sim 10$ & $\sim 11$ & $\sim 424$ & $14 \pm 1$ & FM1000 & Guerreiro et al. (Ref 5) \\
Porous & $\sim 10$ & $\sim 13$ & $\sim 431$ & $13 \pm 1$ & FM1000 & Guerreiro et al. (Ref 5) \\
Porous & $\sim 10$ & $\sim 12$ & $\sim 428$ & $14 \pm 1$ & FM1000 & Guerreiro et al. (Ref 5) \\
Porous & $\sim 10$ & $\sim 12$ & $\sim 432$ & $15 \pm 1$ & FM1000 & Guerreiro et al. (Ref 5) \\
Porous & $\sim 9$ & $\sim 20 \%$ & $\sim 610$ & $\sim 7.5$ & FM1000 & Smith et al. (Ref 25) \\
Porous & $\sim 9$ & $\sim 10 \%$ & $\sim 475$ & $\sim 10.5$ & FM1000 & Smith et al. (Ref 25) \\
DVC & $\sim 9$ & $\sim 3 \%$ & $\sim 1050$ & $\sim 10$ & FM1000 & Smith et al. (Ref 25) \\
Porous & not available & $\sim 21.6$ & $\sim 789$ & $15.3 \pm 0.8$ & FM1000 & Curry et al. (Ref 26) \\
Porous & Not available & $\sim 23$ & $\sim 816$ & $8.2 \pm 1.0$ & FM1000 & Curry et al. (Ref 26) \\
Porous & Not available & $\sim 16.7$ & $600 \pm 100$ & $\sim 8$ & Not available & Lee et al. (Ref 27) \\
Porous & Not available & $\sim 19.6$ & $600 \pm 100$ & $\sim 8$ & Not available & Lee et al. (Ref 27) \\
Porous & Not available & $\sim 12.6$ & $2000 \pm 150$ & $\sim 6$ & Not available & Lee et al. (Ref 27) \\
Porous & Not available & $\sim 18.9$ & $2000 \pm 150$ & $\sim 5$ & Not available Lee et al. (Ref 27) \\
Porous & Not available & $\sim 15$ & $1200 \pm 200$ & $\sim 5.5$ & Not available Myoung et al. (Ref 28) \\
Porous & Not available & $\sim 15$ & $1200 \pm 200$ & $\sim 3$ & Not available Myoung et al. (Ref 28) \\
Porous & Not available & $\sim 10$ & $1200 \pm 200$ & $\sim 6$ & Not available Myoung et al. (Ref 28) \\
Porous & Not available & $\sim 10$ & $1200 \pm 200$ & $\sim 5$ & Not available Myoung et al. (Ref 28) \\
\hline
\end{tabular}

unwanted to due its known stress-induced martensitic transformation. Based on the YSZ phase diagram depicted by Brandon and Taylor (Ref 10), this phase transformation occurs approximately at $100{ }^{\circ} \mathrm{C}$, i.e., very close to RT. Therefore when the $\mathrm{TBC}$ is heated from $\mathrm{RT}$ to turbine operation temperatures, this $m$-YSZ phase (if present) transforms into the tetragonal $(t)$ YSZ phase, which accompanied by a volume shrinkage of 3-5\%. On the contrary, when the TBC cools down to RT, the $t$-YSZ phase transforms again into the $m$-YSZ, which then is followed by a volume expansion of $3-5 \%$. These phase transformations add an additional undesired fatigue stress mode into the TBC system, which helps to lead to early coating spallation. For example, Witz and Bossmann (Ref 29) analyzed the XRD of a delaminated YSZ TBC sample taken from an engine where accelerated TBC degradation was observed. The TBC is composed mostly of $m$-YSZ ( $>70 \mathrm{wt} . \%$ ). For this reason, the presence of $m$-YSZ phase is extremely undesirable in the TBC phase composition.

The $m$-YSZ, if present, can be identified by its $100 \%$ and $70 \%$ highest intensity powder diffraction file (PDF) peaks (PDF \#37-1484); which are found at $2 \theta$ values of $\sim 28.2^{\circ}$ and $\sim 31.5^{\circ}$ for the $\mathrm{CuK} \alpha$ radiation of the XRD. By looking at the XRD pattern of Fig. 6(a), it is possible to notice a minor presence of the $m$-YSZ for the feedstock powder and the total absence of it for the two YSZ TBCs. The minor presence of the $m$-YSZ in the powder is probably related to an incomplete mixture (i.e., alloying) of
$\mathrm{ZrO}_{2}$ and $\mathrm{Y}_{2} \mathrm{O}_{3}$ during the synthesis of the feedstock. The welcome absence of the $m$-YSZ phase in both as-sprayed YSZ TBCs is likely to be related to (i) the high degree of melting of the powder during spraying, which improved its alloying and (ii) the fast cooling rates of the molten YSZ splats during re-solidification upon spraying; as described by of Brandon and Taylor (Ref 10).

The other phase to be identified is the so-called nontransformable tetragonal prime $\left(t^{\prime}\right)$ phase of YSZ (PDF \#48-0224). The $t^{\prime}$-YSZ phase, although metastable, it displays a sluggish phase transformation into the regular tetragonal $(t)$ YSZ (PDF \#82-1245) and cubic (c) YSZ (PDF \#30-1468) up to temperatures of approximately $1300{ }^{\circ} \mathrm{C}$; as described by Brandon and Taylor (Ref 10). Unlike the $t$-YSZ phase, the $t$ '-YSZ phase does not undergo the unwanted martensitic $m$-YSZ phase transformation described above. For this reason, the $t^{\prime}$-YSZ phase is very desirable for a TBC. To properly identify the $t$ '-phase is necessary to distinguish it from the regular tetragonal $t$ phase of YSZ. As both exhibit their $100 \%$ highest intensity diffraction peaks very close to each other, as per Fig. 6(a); it is necessary to look into a second zone of the XRD pattern, which is featured in Fig. 6(b). Essentially, the XRD peaks of the $t^{\prime}$-phase and $t$-phase of YSZ will overlap along the pattern from $20^{\circ}$ to $80^{\circ}$ for the $\mathrm{CuK} \alpha \mathrm{XRD}$ radiation, except at the $2 \theta$ zone around $72-76^{\circ}$. The $t^{\prime}$-YSZ phase will exhibit the diffraction peaks 004 and 220 at $\sim 73.2^{\circ}$ and $\sim 74.2^{\circ}$ (respectively); whereas the $t$-YSZ exhibits the 


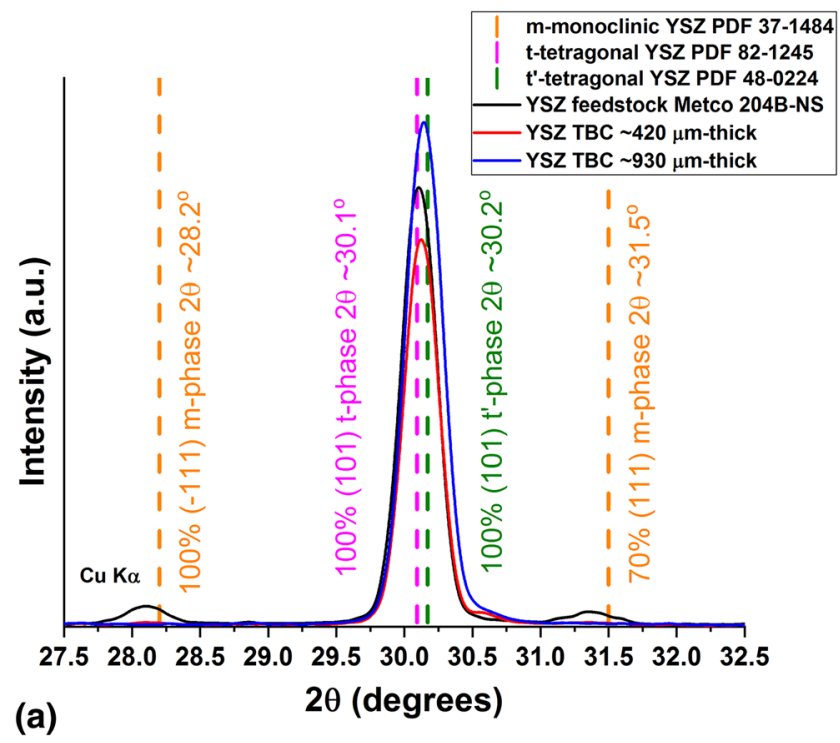

Fig. 6 XRD patterns of the YSZ feedstock and both APS YSZ TBCs: (a) $2 \theta$ from $27.5^{\circ}$ to $32.5^{\circ}$ and (b) $2 \theta$ from $72^{\circ}$ to $76^{\circ}$ diffraction peak $004 / 220$ at $\sim 73.7^{\circ}$. By looking at Fig. 6(b), it is realized that the YSZ powder has the $t^{\prime}$-YSZ as the primary phase (with minor $m$-YSZ phase-Fig. 6a) and both YSZ TBCs only display the well-desired $t$ '-YSZ phase in their compositions. More information about the importance of these YSZ phases, their formations and influence on TBC performance can be found in the work of Brandon and Taylor (Ref 10).

\section{APS YSZ TBC Architectures: Thermal Gradients}

As previously stated, TBCs reduce the temperature of the Ni-based metallic superalloy metallic components located in the hot section of gas turbine engines; which typically exhibit wall thicknesses of $\sim 1-2 \mathrm{~mm}$ and melting points within the $1300-1400{ }^{\circ} \mathrm{C}$ range. According to Rolls-Royce (Ref 30), the maximum temperature that the hot gases inside combustion chamber can reach is $2000{ }^{\circ} \mathrm{C}$ (at its flame core). This gas temperature is subsequently and progressively cooled by cold air that is bled from the turbine compressor and injected along the combustor length (via dilution holes) to reach its specified turbine inlet temperature (TIT). The TIT is the temperature of the combustion gases that leave the combustion chamber and enter the turbine unit.

It needs to be stressed that a turbine engine does not always operate at its peak temperatures. For example, according to the report Commercial Aircraft Propulsion and Energy Systems Research: Reducing Global Carbon Emissions (Ref 31), aviation turbine engines operate at different power levels during each of the distinct segment of a flight. For example, the turbines of commercial jet liners at the take-off will operate at $100 \%$ of their peak

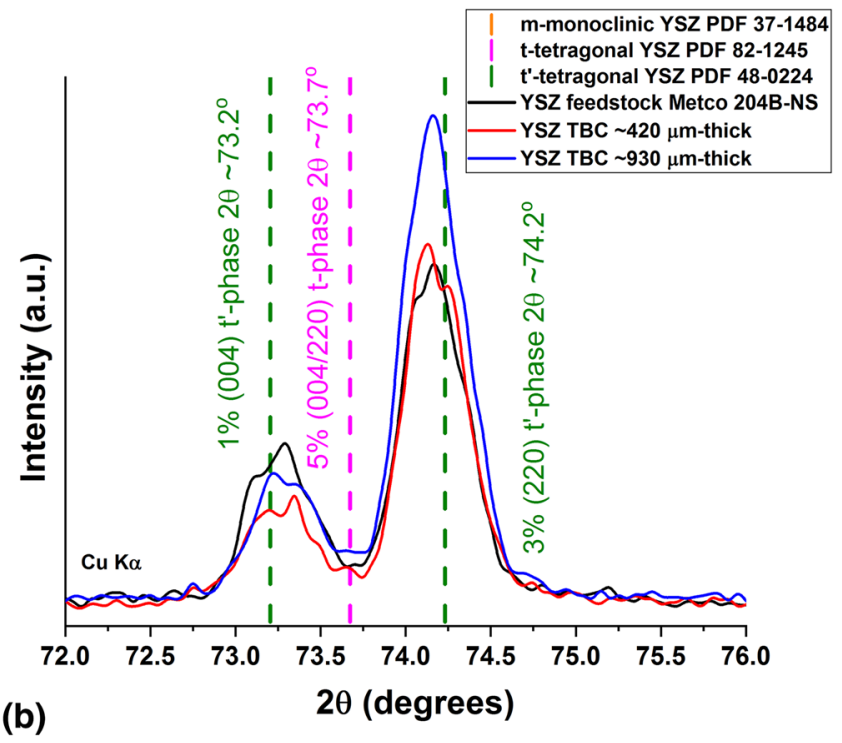

power (which will last for no more than $5 \mathrm{~min}$ ), whereas, during longest stage of the flight (i.e., cruise), they will operate at $30 \%$ of the maximum power. Regarding fighter jets, Mom and Hersback (Ref 32) exemplified that depending on the mission (e.g., from general flying to "dog-fight" mode), maximum military turbine power can be applied from few to several times during a flight mission. According to Farokhi (Ref 33), the TIT levels of modern jet engines during take-off (i.e.; max power) are reaching the range of $1500-1600{ }^{\circ} \mathrm{C}$; whereas these TIT levels during the cruise stage are found within the $1140-1240{ }^{\circ} \mathrm{C}$ range. Regarding IGTs, Nelson and Orenstein (Ref 34) explained that they will operate at lower maximum peak temperatures than those of aviation turbines, but at much longer and continuous times $(>20,000$ h). As a complement note, YSZ TBCs are not supposed to temperatures higher than $\sim 1300{ }^{\circ} \mathrm{C}$, as discussed in "Understanding Thermal Gradients within TBCs and Metallic Components" section, even if TIT levels reach $1500-1600{ }^{\circ} \mathrm{C}$ at take-off engine power. A thin air film cooling (bled from the compressor) will flow adjacent to the TBC surface from specifically engineered cooling holes in the components, thereby providing a "cooler shielding layer" over the TBC surface (in addition to the uncoated component backside), as described in details by RollsRoyce (Ref 30) and Farokhi (Ref 33). Finally, Witz and Bossmann (Ref 29) analyzed ex-serviced real TBC-coated components of turbine engines. Their objective of the study was to determine the real surface temperature that TBCs were subjected during engine operation (via thermal paint and XRD analysis); in order to create mappings of the TBC thermal load and a lifetime evaluation model. One of the parts analyzed was a $\sim 20 \mathrm{~cm} \mathrm{x} \sim 20 \mathrm{~cm}$ TBC-coated heat- 
tile originating from the combustion chamber. Via a thermal paint evaluation along the length of the tile, it was observed that during the life of engine operation, the TBC on this single component had experienced a variation of maximum temperature of up $150{ }^{\circ} \mathrm{C}$ across its $\sim 20 \mathrm{~cm}$ extent, with the max peak located around center of the tile. Thus, based on the examples above cited, one can realize that the knowledge of the temperature drop (i.e., reduction) provided by a TBC on a coated component, over a wide range of (i) component locations, (ii) TBC thicknesses and (iii) surface temperatures, is essential for modelling, simulation and lifetime prediction. And these sets of data are scarce in the open literature.

To help addressing this need, the data profiles of the two $14 \%$ porous APS YSZ TBC samples of this study generated by the laser-rig can be found in Fig. $7(\sim 420 \mu \mathrm{m}$ thick YSZ TBC) and Fig. 8 ( $~ 930 \mu \mathrm{m}$-thick YSZ TBC). It includes the YSZ TBC surface temperature (T-ysz), the substrate temperature ( $\mathrm{T}$-sub), the laser power and the back-side air cooling for the un-coated side of the coupons. Some important characteristics are shared for both testing. After an initial laser-rig stabilization period of $\sim 2 \mathrm{~min}$, the profiles generated were essentially constant for nearly $30 \mathrm{~min}$. As stated, the back cooling air jet on the uncoated side of the coupons was set at $\sim 430 \mathrm{lpm}$ for all samples. Consequently, all these TBC-coated samples are being tested under virtually identical cooling conditions. For this reason, to increase T-ysz from $1100{ }^{\circ} \mathrm{C}$ to higher values, the laser power had to be increased. On the same note, the higher the T-ysz, the higher the T-sub (as expected). It is important to remember that the T-sub was measured via a thermocouple inserted the mid-thickness of the substrate, located $1.6 \mathrm{~mm}$ beneath the $\mathrm{BC} /$ substrate interface. Therefore, the T-sub values measured in this experiment are considered to be representative of those of a back-side component (e.g., combustion chamber), if its total wall thickness was $1.6 \mathrm{~mm}$.

As all $\triangle \mathrm{T}$ s for all TBCs in the individual testing conditions depicted in Fig. 7(a)-(e) and 8(a)-(g) are consistent and steady; i.e., parallel to each other, it can be said that any significant YSZ sintering/densification events that might have occurred, were minor and did not affect the experiment in some significant way. In other words, if a significant YSZ sintering was taking place during testing, the T-ysz and T-sub profiles would become tapered towards each other. On that account, it is fair to say that the data reported in this work (Fig. 7-8) represent the $\Delta \mathrm{T}$ temperature reduction values that occur across TBC/substrate systems for an as-sprayed $14 \%$ porous APS YSZ TBC, manufactured at two thickness levels and subjected to distinct T-ysz values but the same cooling.

As explained in the "YSZ Elastic Modulus via Instrumented Indentation Testing" section of this manuscript, the
T-ysz was increased from $1100{ }^{\circ} \mathrm{C}$ in $100{ }^{\circ} \mathrm{C}$ steps (by augmenting laser power) until the temperature of the substrate (T-sub) reached around $1000{ }^{\circ} \mathrm{C}$; which is typically considered to be the highest limit of temperature operation for static gas turbine components (e.g., combustor). Figure 9 and 10 highlight in more detail the data displayed in Fig. 7 and 8.

For example, Fig. 9 depicts the resulting T-sub values as a function of the pre-selected T-ysz levels for both TBCs. For the $\sim 420 \mu \mathrm{m}$-thick YSZ TBC, when T-ysz is $\sim 1300{ }^{\circ} \mathrm{C}$ (typically considered at the YSZ upper temperature limit), the resulting T-sub is $\sim 875^{\circ} \mathrm{C}$; which is well below the generally accepted T-sub of $1000{ }^{\circ} \mathrm{C}$. T-sub will only reach $1000{ }^{\circ} \mathrm{C}$, when T-ysz approaches $1500{ }^{\circ} \mathrm{C}$. On the other hand, for the $\sim 930 \mu \mathrm{m}$-thick YSZ TBC, this $1000{ }^{\circ} \mathrm{C}$ T-sub max limit could not be reached. The reason was, the highest calibrated temperature of the laser-rig pyrometer was $1684^{\circ} \mathrm{C}$. Consequently, the laser power was elevated and stopped at $511 \mathrm{~W}$, when T-ysz had reached $\sim 1680{ }^{\circ} \mathrm{C}$; which corresponded to a $\mathrm{T}$-sub of $\sim 880^{\circ} \mathrm{C}$ (Fig. 8g).

The specific temperature drop levels $(\Delta \mathrm{Ts})$ across the TBC/substrates thickness profile are featured in Fig. 10. Once again, when T-ysz is $\sim 1300{ }^{\circ} \mathrm{C}$ for $\sim 420 \mu \mathrm{m}$-thick YSZ TBC, the resulting temperature reduction to the substrate is $\sim 425{ }^{\circ} \mathrm{C}$. For $\sim 930 \mu \mathrm{m}$-thick YSZ TBC, at the very same T-ysz of $\sim 1300^{\circ} \mathrm{C}$, the resulting temperature reduction to the substrate is $\sim 600^{\circ} \mathrm{C}$. These results point up the higher thermal resistance displayed by the thicker coating, as discussed by Helminiak et al. (Ref 15). And although YSZ TBCs were not developed to work at a T-ysz of $1680{ }^{\circ} \mathrm{C}$, for sure one cannot fail to notice the "remarkable" temperature reduction of $800{ }^{\circ} \mathrm{C}$ to the substrate yielded by the thicker TBC (Fig. 10).

Finally, based on the references discussed above, it is important to remember again that gas turbine engines operate at different temperature regimes and the thermal load over TBC-coated component will vary depending on the part location. The TBC temperature mappings, such as that proposed by Witz and Bossmann (Ref 29), are very useful to pin-point temperature profiles and hot-spots. For these reasons, a better understanding of the $\Delta$ Ts that take place along the $\mathrm{TBC} /$ component profile is of high importance for improving the manufacturing efficiency and lifetime of TBCs. For example, the thicknesses of the TBCs can be bespoken based on the previously-mapped thermal loads across the component. Most likely this approach could be "more easily" implemented in float wall type of combustion chambers. In this configuration, the walls of a combustor are lined by a multi-assembly of individual TBC-coated heat tiles that protect the body of the combustor liner from damage due to exposure with the hot gases. 

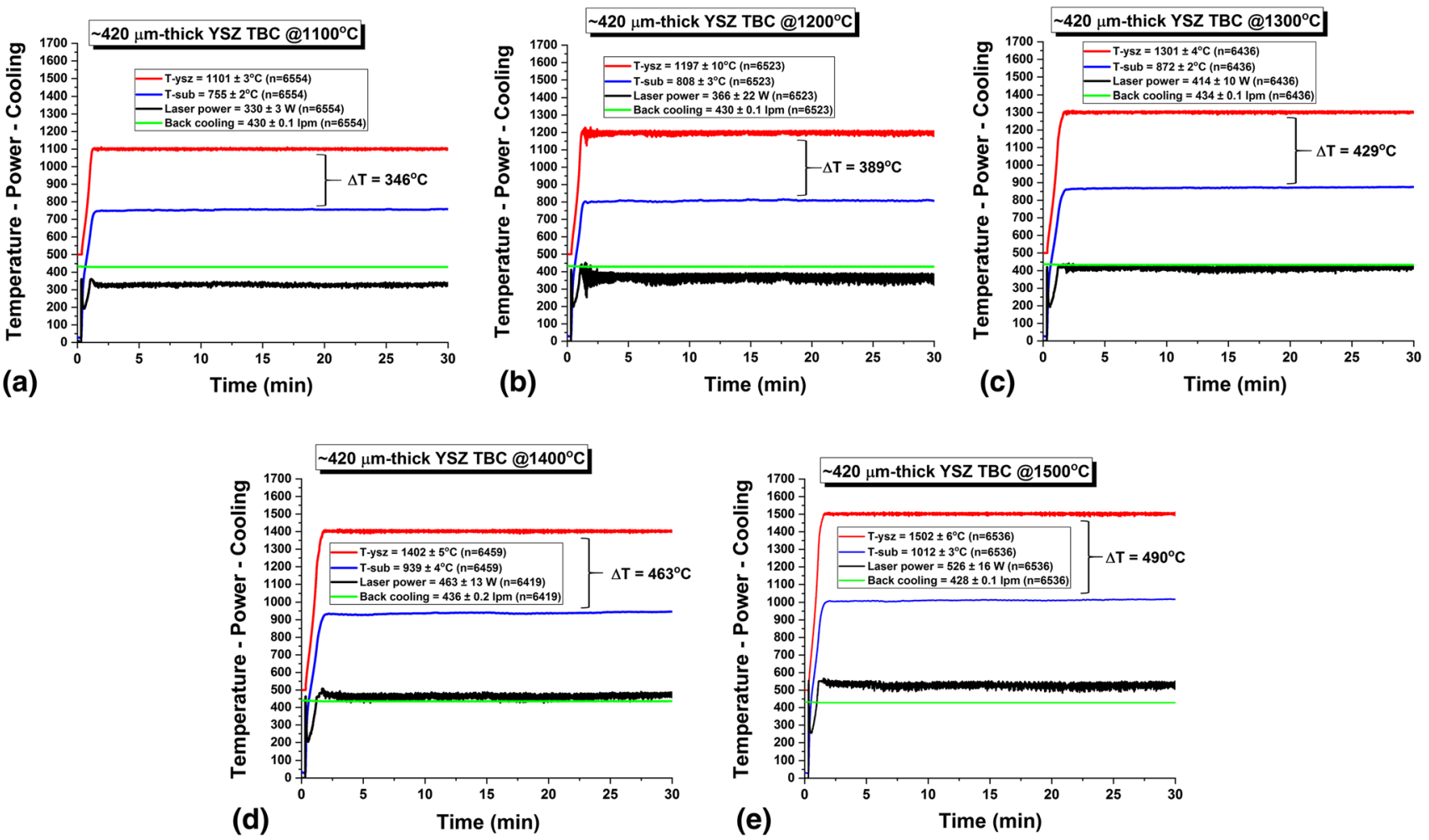

Fig. 7 Laser-rig thermal gradient results for the $\sim 420 \mu$ m-thick YSZ TBC at the following T-ysz pre-sets: (a) T-ysz $1100{ }^{\circ} \mathrm{C}$; (b) T-ysz 1200 ${ }^{\circ} \mathrm{C}$; (c) T-ysz $1300{ }^{\circ} \mathrm{C}$; (d) T-ysz $1400{ }^{\circ} \mathrm{C}$ and (e) T-ysz $1500{ }^{\circ} \mathrm{C}$

\section{YSZ TBC Manufacturing Cost Estimation}

The high powder feed rate and DE values obtained for the YSZ TBC manufacturing reported in this manuscript can be considered very promising. However, one may claim that in real production environment, the elevated plasma gas flow levels and electrical energy consumption required by a high-enthalpy torch like the Axial III Plus would overshadow its gains when compared to the performance of a legacy torch.

To address this issue, the YSZ TBC manufacturing cost estimation was based on the data gathered during this study and also on results obtained in previous works (Ref 4, 5). The estimation was based on the calculation performed to spray a $410-430 \mu \mathrm{m}$ thick YSZ TBC on a $500 \mathrm{~mm}$ long cylinder component, using spray parameters developed in this research for the Axial III Plus torch, as well as, that of a legacy APS $\mathrm{Ar} / \mathrm{H}_{2}$ torch; which was sprayed a YSZ at powder feed rate of $60 \mathrm{~g} / \mathrm{min}$, displayed a porosity level of $\sim 13 \%$ and exhibited a DE value of $43 \%$ (Ref 5). This component part could be considered as being similar to the inner wall of an annular turbine combustion chamber. The component tangential speed, the torch transverse speed, powder feed rate, DR and DE values used to estimate the cost and time to deposit the TBC were the ones used and obtained from these studies. The cost of the consumables and energy were: $30 \mathrm{US} \$ / \mathrm{m}^{3}$ for $\mathrm{Ar}, 22 \mathrm{US} \$ / \mathrm{m}^{3}$ for $\mathrm{N}_{2}, 38$ $\mathrm{US} \$ / \mathrm{m}^{3}$ for $\mathrm{H}_{2}, 34 \mathrm{US} \$ / \mathrm{kg}$ for YSZ feedstock and 0.25 $\mathrm{kWh}$ for electricity. Other costs involved (e.g., labor) were not included in the estimation.

Briefly, by changing from an $\mathrm{Ar} / \mathrm{H}_{2}$ legacy plasma torch to a $\mathrm{N}_{2}$-based high-enthalpy one, there is a reduction of (i) $66 \%$ in processing time, (ii) $44 \%$ in YSZ feedstock consumption, (iii) $21 \%$ in plasma gas cost, (iv) $44 \%$ in electricity cost, and (v) $60 \%$ in total manufacturing cost. As previously stated, reducing environmental footprint means reducing at the same time the amount of natural resources and energy used to produce a product. Consequently, these sets of data exemplify the possible gains of manufacturing efficiency by using $\mathrm{N}_{2}$-based high-enthalpy APS torches for YSZ TBC production.

\section{Final Comments}

Regarding manufacturing efficiency, although the results obtained in this work are promising, there are still important steps to be investigated in order to confirm the applicability of these types of high feed rate and high DE APS YSZ TBCs in industrial applications. Among these steps are (i) YSZ thermal conductivity measurements, (ii) erosion testing and (iii) TBC thermal cycling performance. Regarding thermal conductivity measurements, the as- 

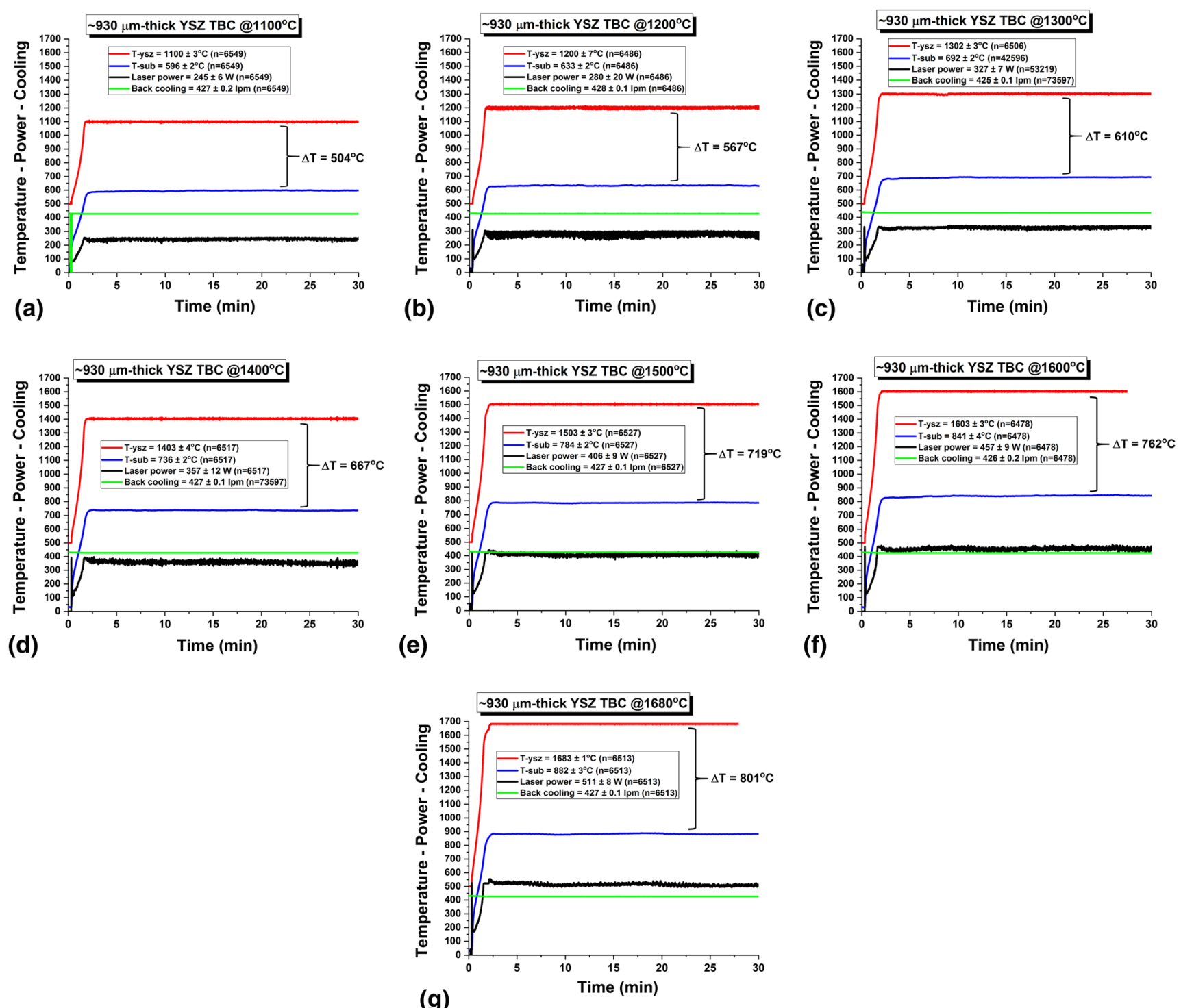

Fig. 8 Laser-rig thermal gradient results for the $\sim 930 \mu \mathrm{m}$-thick YSZ TBC at the following T-ysz pre-sets: (a) T-ysz $1100{ }^{\circ} \mathrm{C}$; (b) T-ysz 1200 ${ }^{\circ} \mathrm{C}$; (c) T-ysz $1300{ }^{\circ} \mathrm{C}$; (d) T-ysz $1400{ }^{\circ} \mathrm{C}$; (e) T-ysz $1500{ }^{\circ} \mathrm{C}$; (f) T-ysz $1600{ }^{\circ} \mathrm{C}$ and (g) T-ysz $1680{ }^{\circ} \mathrm{C}$

sprayed YSZ value most likely will fall within those reported in the literature for $10-15 \%$ porous YSZ TBCs; i.e., $0.8-1.0 \mathrm{~W} / \mathrm{mK}(\operatorname{Ref} 1,4,5)$. Thus, no unexpected surprises should occur here. The same hypothesis can be stated for erosion testing; considering the fact that the TBC manufactured in this study exhibits a conventional porous microstructure. But for sure an investigation on the thermal cycling performance (including a comparison with a TBC benchmark) is paramount.

With respect to the thermal gradient study, it is recognized that TBCs will sinter in time in these thermal gradient conditions, as described by Zhu and Miller (Ref 35) when using a laser-rig to create thermal gradients on TBCs. Since thermal gradient tests, such as burner and laser-rig are time consuming (and thereby costly), in order to provide sufficient statistics of samples to develop TBC aging models, most likely the combination of thermal gradient testing and the Larson-Miller parameter will be necessary. Larson-Miller parameter describes the creeplike behavior of thermal conductivity increase with temperature and time for different materials. For TBC R\&D, this concept has been introduced by Zhu and Miller (Ref 35) and further explored by Tan et al. (Ref 36).

Moreover, it needs to be stressed that this work is not claiming (at all) that APS YSZ TBCs can be safety operated at temperatures higher than $1300{ }^{\circ} \mathrm{C}$ for long hours in gas turbine engines. The reasons for this $1300{ }^{\circ} \mathrm{C} \mathrm{YSZ}$ limitation are well-known, stated and discussed in "Understanding Thermal Gradients within TBCs189 and Metallic Components" section. The objective here is to 


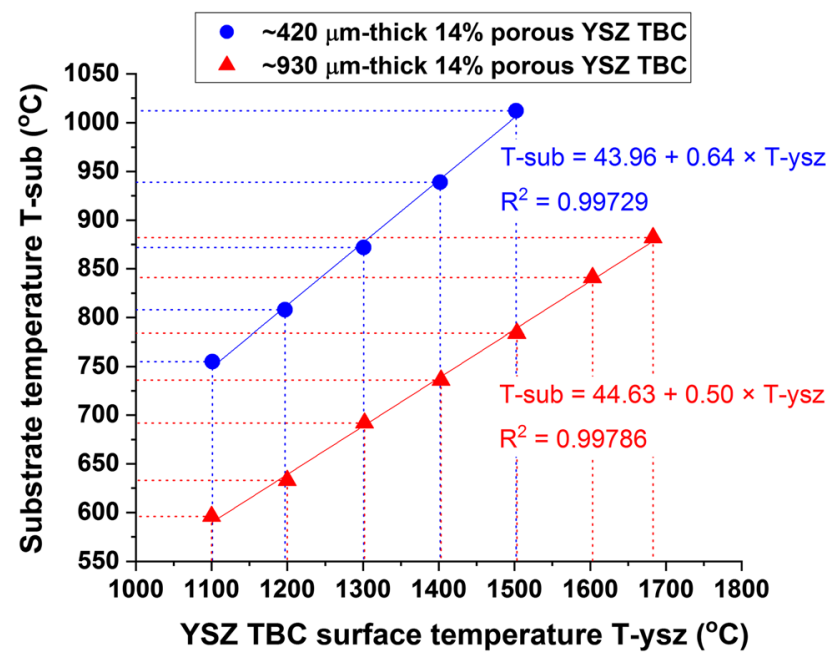

Fig. 9 Resulting T-sub values as a function of T-ysz pre-sets for the two APS TBC architectures: $\sim 420 \mu$ m-thick YSZ TBC and $\sim 930$ $\mu \mathrm{m}$-thick YSZ TBC

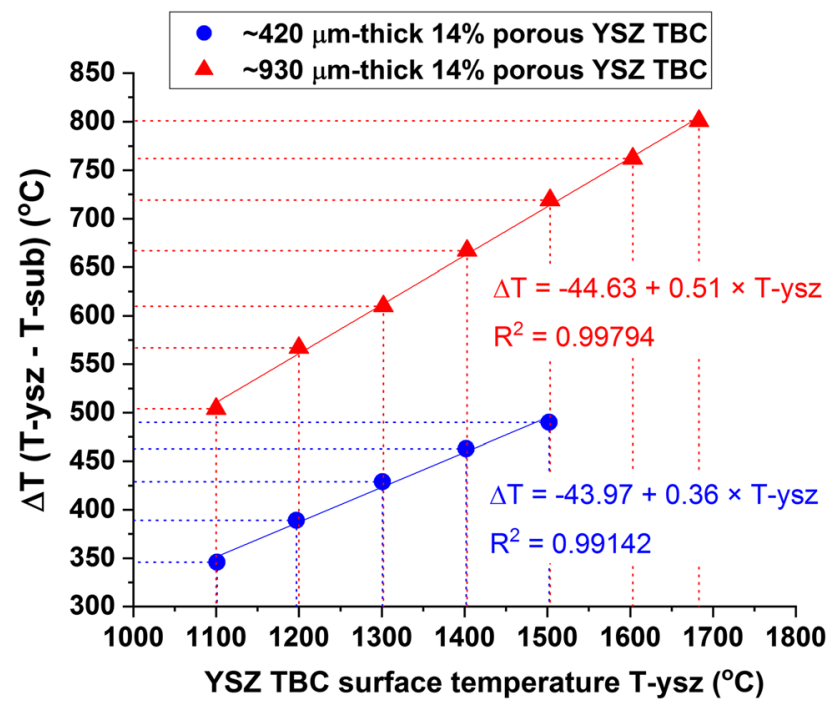

Fig. 10 Resulting $\Delta \mathrm{T}$ (T-ysz-T-sub) values as a function of T-ysz pre-sets for the two APS TBC architectures: $\sim 420 \mu \mathrm{m}$-thick YSZ TBC and $\sim 930 \mu \mathrm{m}$-thick YSZ TBC

provide engineering data for a better comprehension on how hot-section components of gas turbine are protected by TBCs. Consequently, a wide range of T-ysz values were investigated, including the ones above the $1300{ }^{\circ} \mathrm{C}$ limit. It is another complement to previous study (Ref 14), where (i) the same laser-rig equipment was employed to generate thermal gradients on porous APS YSZ TBCs at a T-ysz magnitude of $1300{ }^{\circ} \mathrm{C}$ and (ii) other TBC thermal gradient results reported in the literature were summarized.

Finally, by looking at the results of the thicker YSZ TBC (Fig. 8, 9, 10), one may wonder or even speculate about a possible thermal insulation protection that a thick (e.g., $\sim 900-1000 \mu \mathrm{m}$ ) and porous (e.g., 10-20\%) multi- layer TBC assembly could offer to these metallic components. A TBC assembly, which one of the layers could even be YSZ, but with the addition to other newly-developed over-layers. New high-performance ceramics engineered to display at high temperatures a combination some key characteristics; including (i) low thermal conductivity, (ii) phase stability, (iii) CMAS-attack resistance, (iv) erosion resistance and (iv) chemical endurance against water vapor attack. If achievable, this type of multi-layer TBC assembly could potentially operate at temperatures well-over the established $1300{ }^{\circ} \mathrm{C}$ limit for YSZ and still keep the current Ni-based superalloy components at temperatures no higher than $1000{ }^{\circ} \mathrm{C}$. And if attainable, this type of multi-layer TBC assembly and Ni-based superalloy architecture may possibly be an alternative to environmental barrier coatings (EBCs) and ceramic matrix composites (CMCs).

\section{Conclusions}

This engineering paper demonstrated that a high-enthalpy $\mathrm{N}_{2}$-based APS torch (Axial III Plus) can be successfully employed to manufacture a conventional $\sim 14 \%$ porous YSZ TBC at high powder feed rate $(100 \mathrm{~g} / \mathrm{min})$ and DE value $(70 \%)$. Two YSZ TBCs displaying thicknesses of $\sim 420$ and $\sim 930 \mu \mathrm{m}$ were deposited using the identical set of optimized spray parameters over the same type of $\sim 160$ $\mu \mathrm{m}$-thick MCrAlY APS bond-coated coupons. Both YSZ TBCs did not show segmented cracking, horizontal interlayer delamination or adhesion defects. In fact, the bond strength levels (ASTM C633) were $13 \mathrm{MPa}(\sim 420 \mu \mathrm{m}$ thick TBC) and 11.6 MPa ( $930 \mu \mathrm{m}$-thick TBC); which are among the upper adhesion values for APS YSZ TBCs reported in the literature (i.e., typically 7-15 MPa). Therefore, even though one YSZ TBC is twice thicker than the other, the drop of bond strength intensity for the thicker coating was only $11 \%$. Regarding phase composition, the two TBCs exhibited solely the desirable $t$ '-phase of YSZ.

With respect to the thermal insulating effectiveness of as-sprayed $\sim 14 \%$ porous APS YSZ TBCs, the following results are highlighted. The thermal gradient laser-rig data have shown that for the $\sim 420 \mu \mathrm{m}$-thick YSZ TBC at YSZ surface temperatures (T-ysz) ranging from 1100 to $1500{ }^{\circ} \mathrm{C}$, the resulting substrate temperatures (T-sub) values stretched from 750 to $1000{ }^{\circ} \mathrm{C}$. For the $\sim 930 \mu \mathrm{m}$-thick YSZ TBC, the YSZ surface temperature (T-ysz) level was extended from 1100 up to $1680{ }^{\circ} \mathrm{C}$; and the resulting substrate temperatures (T-sub) varied from 600 to $880{ }^{\circ} \mathrm{C}$. The $\Delta \mathrm{T}$ results confirm the higher thermal resistance of the thicker YSZ when both TBCs operate within the same $\mathrm{T}$-ysz reach. In addition, at a T-ysz of $1680^{\circ} \mathrm{C}$, the $\sim 930 \mu \mathrm{m}$-thick YSZ TBC yielded temperature reduction of $800{ }^{\circ} \mathrm{C}$ to the substrate. It is thought that these results 
will be important for engineers working on the modelling/ simulation of the performance and longevity of TBCcoated turbine components.

Although further investigation (e.g.; thermal cycling performance) is necessary to confirm the applicability of these TBCs in industrial environments; the initial results of this work are promising regarding the possibility of improving considerably the manufacturing efficiency of porous YSZ TBCs by using a high-enthalpy $\mathrm{N}_{2}$-based APS torch.

Acknowledgments The author would like to acknowledge the contribution of the following Technical Officers (TOs) of the NRC: David Delagrave for metallography preparation and Karine Théberge for SEM-EDX and instrumented indentation evaluation. NRC's Associate Research Officer (AcSO) Bruno Guerreiro help in operating the XRD equipment is highly appreciated. Finally, very special thanks to the NRC TO Jean-Claude Tremblay for (i) commissioning the Axial III Plus APS torch at the NRC, (ii) TBC manufacturing and (iii) thermal gradient laser-rig testing.

Open Access This article is licensed under a Creative Commons Attribution 4.0 International License, which permits use, sharing, adaptation, distribution and reproduction in any medium or format, as long as you give appropriate credit to the original author(s) and the source, provide a link to the Creative Commons licence, and indicate if changes were made. The images or other third party material in this article are included in the article's Creative Commons licence, unless indicated otherwise in a credit line to the material. If material is not included in the article's Creative Commons licence and your intended use is not permitted by statutory regulation or exceeds the permitted use, you will need to obtain permission directly from the copyright holder. To view a copy of this licence, visit http://creativecommons. org/licenses/by/4.0/.

\section{References}

1. A. Feuerstein, J. Knapp, T. Taylor, A. Ashary, A. Bolcavage and N. Hitchman, Technical and Economical Aspects of Current Thermal Barrier Coating Systems for Gas Turbine Engines by Thermal Spray and EBPVD: A Review, J. Therm. Spray Technol., 2008, 17(2), p 199-213.

2. S. Sampath, U. Schulz, M.O. Jarligo and S. Kuroda, Processing Science of Advanced Thermal-Barrier Systems, MRS Bull., 2012, 37(7), p 903-910.

3. B.R. Marple, R.S. Lima, C. Moreau, S.E. Kruger, L. Xie and M.R. Dorfman, Yttria-Stabilized Zirconia Thermal Barriers Sprayed Using $\mathrm{N}_{2}-\mathrm{H}_{2}$ and Ar- $\mathrm{H}_{2}$ Plasmas: Influence of Processing and Heat Treatment on Coating Properties, J. Therm. Spray Technol., 2007, 16(5-6), p 791-797.

4. R.S. Lima, B.M.H. Guerreiro, N. Curry, M. Leitner and K. Körner, Environmental, Economical, and Performance Impacts of Ar- $\mathrm{H}_{2}$ and $\mathrm{N}_{2}-\mathrm{H}_{2}$ Plasma-Sprayed YSZ TBCs, J. Therm. Spray Technol., 2020, 29(1-2), p 74-89.

5. B.M.H. Guerreiro, R.S. Lima, N. Curry, M. Leitner and K. Körner, The Influence of Plasma Composition in the Thermal Cyclic Performance of Yttria-Stabilized Zirconia (8YSZ) Thermal Barrier Coatings (TBCs), J. Therm. Spray Technol., 2021, 20(1-2), p 59-68.

6. V. Belashchenko and A. Zagorski, "High Stability, High Enthalpy APS Process Based on Combined Wall and Gas
Stabilizations of Plasma (Part 2: Plasma Properties and Process Operating Window)", Proceedings of the International Thermal Spray Conference, May 11-14, 2015, Long Beach, CA, USA, (Ed.) A. McDonald, A. Agarwal, G. Bolelli, A. Concustell, Y.-C. Lau, F.-L. Toma, E. Turunen and C. Wildener, ASM International, Materials Park, OH, USA, p 184-191, 2015

7. A.B. Murphy and C.J. Arundell, Transport Coefficients of Argon, Nitrogen, Oxygen, Argon-Nitrogen, and Argon-Oxygen Plasmas, Plasma Chem. Plasma Process., 1994, 14(4), p 451-490.

8. A. El-Zein, M. Talaat, G. El-Aragi and A. El-Amawy, Electrical Characteristics of Nonthermal Gliding Arc Discharge Reactor in Argon and Nitrogen Gases, IEEE Trans. Plasma Sci., 2016, 44(7), p 1155-1159.

9. M.P. Borom, C.A. Johnson and L.A. Peluso, Role of Environmental Deposits and Operating Surface Temperature in Spallation of Air Plasma Sprayed Thermal Barrier Coatings, Surf. Coat. Technol., 1996, 86-87, p 116-126.

10. J.R. Brandon and R. Taylor, Phase Stability of Zirconia-Based Thermal Barrier Coatings Part I: Zirconia-Yttria Alloys, Surf. Coat. Technol., 1991, 46, p 75-90.

11. J.A. Thompson and T.W. Clyne, The Effect of Heat Treatment on the Stiffness of Zirconia Top Coats in Plasma-sprayed TBCs, Acta Mater., 2001, 49, p 1565-1575.

12. R. Vaßen, S. Giesen and D. Stover, Lifetime of Plasma-Sprayed Thermal Barrier Coatings: Comparison of Numerical and Experimental Results, J. Therm. Spray Technol., 2009, 18(5-6), p 835-845.

13. High-Temperature High-Strength Nickel Base Alloys, 2021, https://fdocuments.in/download/no-393-nickel-inst-mediafiles technicalliteraturehighno-393-subject-high-temperature

14. R.S. Lima, Perspectives on Thermal Gradients in Porous ZrO27-8 wt.\% Y2O3 (YSZ) Thermal Barrier Coatings (TBCs) Manufactured by Air Plasma Spray (APS), Coatings, 2020, 10(812), p 1-18.

15. M.A. Helminiak, M.N. Yanar, F.S. Pettit, T.A. Taylor and G.W. Meier, Factors Affecting the Microstructure Stability and Durability of Thermal Barrier Coatings Fabricated by Air Plasma Spraying, Mater. Corros., 2012, 63(10), p 929-939.

16. ASTM C633 - Standard Test Method for Adhesion or Cohesion Strength of Thermal Spray Coatings, ASTM International, West Conshohocken, PA, USA.

17. W.C. Oliver and G.M. Pharr, Measurement of Hardness and Elastic Modulus by Instrumented Indentation: Advances in Understanding and Refinements to Methodology, J. Mater. Res., 2004, 19(1), p 3-20.

18. L. González-Fernández, L. del Campoa, R.B. Pérez-Sáeza and M.J. Telloa, Normal Spectral Emittance of Inconel 718 Aeronautical Alloy Coated with Yttria Stabilized Zirconia Films, $J$. Alloy. Compd., 2012, 513, p 101-106.

19. A. Schmidt, H. Aleksanoglu, T. Mao, A. Scholz and C. Berger, Influence of Bond Coat Roughness on Life Time of APS Thermal Barrier Coatings Systems under Thermal-Mechanical Load, $J$. Solid Mech. Mater. Eng., 2010, 4(2), p 208-220.

20. R. Eriksson, S. Sjöström, H. Brodin, S. Johanssona, L. Östergrenc and X.-H. Li, TBC Bond Coat-Top Coat Interface Roughness: Influence on Fatigue Life and Modelling Aspects, Surf. Coat. Technol., 2013, 236, p 230-238.

21. J.A. Haynes, M.K. Ferber and W.D. Porter, Thermal Cycling Behavior of Plasma-Sprayed Thermal Barrier Coatings with Various MCrAIX Bond Coats, J. Therm. Spray Technol., 2000, 9(1), p 38-48.

22. H.P. Bossmann, G. Witz and R. Baumann, Development of Reliable Thermal Barrier Coatings for high-loaded Turbine and Combustor Parts, VGB PowerTech, 2011, 91(10), p 50-54.

23. R. Vaßen, F. Traeger and D. Stöver, Correlation Between Spraying Conditions and Microcrack Density and Their Influence 
on Thermal Cycling Life of Thermal Barrier Coatings, J. Therm. Spray Technol., 2004, 13(3), p 396-404.

24. S.V. Shinde, E.J. Gildersleeve, C.A. Johnson and S. Sampath, Segmentation Crack Formation Dynamics During Air Plasma Spraying of Zirconia, Acta Mater., 2020, 183, p 196-206.

25. J. Smith, J. Scheibel, D. Classen, S. Paschke, S. Elbel, K. Fick and D. Carlson, Thermal Barrier Coating Validation Testing for Industrial Gas Turbine Combustion Hardware, J. Eng. Gas Turbines Power, 2016, 138(3), p 215-220.

26. N. Curry, M. Leitner and K. Körner, High-Porosity Thermal Barrier Coatings from High-Power Plasma Spray EquipmentProcessing Performance and Economics, Coatings, 2020, 10(957), p 1-25.

27. P.-H. Lee, S.-Y. Lee, J.-Y. Kwon, S.-W. Myoung, J.-H. Lee, Y.G. Jung, H. Cho and U. Paik, Thermal Cycling Behavior and Interfacial Stability in Thick Thermal Barrier Coatings, Surf. Coat. Technol., 2010, 205, p 1250-1255.

28. S.-W. Myoung, Z. Lu, Y.-G. Jung, B.-K. Jang, Y.-S. Yoo, S.-M. Seo, B.-G. Choi and C.-Y. Jo, Effect of Plasma Pretreatment on Thermal Durability of Thermal Barrier Coatings in Cyclic Thermal Exposure, Adv. Mater. Sci. Eng., 2014 https://doi.org/10. $1155 / 2014 / 593891$

29. G. Witz and H.-P. Bossmann, Determination of Thermal Barrier Coatings Average Surface Temperature After Engine Operation for Lifetime Validation, J. Eng. Gas Turbines Power, 2012, 134, p 122507-1-7.
30. Rolls-Royce. The Jet Engine, (2020), http://www.valentiniweb. com/Piermo/meccanica/mat/Rolls\%20Royce\%20\%20The\% 20Jet\%20Engine.pdf

31. Academies of Sciences, Engineering, and Medicine-Commercial Aircraft Propulsion and Energy Systems Research: Reducing Global Carbon Emissions, (2020), https://www.nap.edu/catalog/ 23490/commercial-aircraft-propulsion-and-energy-systemsresearch-reducing-global-carbon

32. A. Mom and H. Hersbach, Performance of High Temperature Coatings on F100 Turbine Blades Under Simulated Service Conditions, Mater. Sci. Eng., 1987, 87, p 361-367.

33. S. Farokhi, Aircraft Propulsion, 2nd ed.; Wiley: Chichester, West Sussex, UK, pp. 7-9, p 483-488 (2015)

34. W.A. Nelson and R.M. Orenstein, TBC Experience in LandBased Gas Turbines, J. Therm. Spray Technol., 1997, 6, p 176-180.

35. D. Zhu and R.A. Miller, Thermal Conductivity and Elastic Modulus Evolution of Thermal Barrier Coatings under High Heat Flux Conditions, J. Therm. Spray Technol., 2000, 9, p 175-180.

36. Y. Tan, J.P. Longtin, S. Sampath and H. Wang, Effect of the Starting Microstructure on the Thermal Properties of As-sprayed and Thermally Exposed Plasma-Sprayed YSZ Coatings, J. Am. Ceram. Soc., 2009, 92(3), p 710-716.

Publisher's Note Springer Nature remains neutral with regard to jurisdictional claims in published maps and institutional affiliations. 